\title{
A survey of TIR domain sequence and structure divergence
}

\author{
Vladimir Y. Toshchakov ${ }^{1}$ (D) - Andrew F. Neuwald ${ }^{2}$ (D) \\ Received: 23 October 2019 / Accepted: 20 January 2020 / Published online: 30 January 2020 \\ (C) The Author(s) 2020, corrected publication 2021
}

\begin{abstract}
Toll-interleukin-1R resistance (TIR) domains are ubiquitously present in all forms of cellular life. They are most commonly found in signaling proteins, as units responsible for signal-dependent formation of protein complexes that enable amplification and spatial propagation of the signal. A less common function of TIR domains is their ability to catalyze nicotinamide adenine dinucleotide degradation. This survey analyzes 26,414 TIR domains, automatically classified based on group-specific sequence patterns presumably determining biological function, using a statistical approach termed Bayesian partitioning with pattern selection (BPPS). We examine these groups and patterns in the light of available structures and biochemical analyses. Proteins within each of thirteen eukaryotic groups (10 metazoans and 3 plants) typically appear to perform similar functions, whereas proteins within each prokaryotic group typically exhibit diverse domain architectures, suggesting divergent functions. Groups are often uniquely characterized by structural fold variations associated with group-specific sequence patterns and by herein identified sequence motifs defining TIR domain functional divergence. For example, BPPS identifies, in helices C and D of TIRAP and MyD88 orthologs, conserved surface-exposed residues apparently responsible for specificity of TIR domain interactions. In addition, BPPS clarifies the functional significance of the previously described Box 2 and Box 3 motifs, each of which is a part of a larger, group-specific block of conserved, intramolecularly interacting residues.
\end{abstract}

Keywords TIR domains · Bayesian partitioning with pattern selection · Protein function · Protein structure

\section{Introduction}

Toll-interleukin-1R resistance (TIR) domains most commonly function as signaling units responsible for transient, signaldependent associations among TIR-containing proteins that enable amplification and spatial propagation of the signal (Pawson and Nash 2003). TIR domains were first recognized as a region of homology between Drosophila Toll protein and human IL-1 receptor (IL-1R) (Gay and Keith 1991). Other $\mathrm{TIR}$ domains were found in resistance proteins ( $\mathrm{R}$ proteins)

Electronic supplementary material The online version of this article (https://doi.org/10.1007/s00251-020-01157-7) contains supplementary material, which is available to authorized users.

Vladimir Y. Toshchakov

vtoshchakov@som.umaryland.edu

1 Department of Microbiology and Immunology, University of Maryland School of Medicine, Baltimore, MD 21201, USA

2 Department of Biochemistry and Molecular Biology, University of Maryland School of Medicine, Baltimore, MD 21201, USA
(Whitham et al. 1994), plant receptors that sense the presence of phytopathogens on the gene-for-gene basis and that activate programmed cell death at the infection site (Spoel and Dong 2012; Van der Biezen and Jones 1998). Metazoan TIRcontaining proteins are generally involved in the innate immune defense mechanisms against single-celled pathogens, viruses, and multicellular parasites (Kawai and Akira 2011). The Toll proteins of insects, in addition to their role in immunity, participate in dorsoventral polarization in early embryogenesis (Anderson et al. 1985; Lemaitre et al. 1996). TIR domains, however, are not restricted to multicellular organisms, as they are widespread among all major bacterial phyla (Ve et al. 2015), and occur in archaea and fungi. Some TIR domains found in pathogenic microbes may function to subvert immune defenses of higher organisms (Rana et al. 2013). The broad phylogenetic distribution of TIR-containing proteins among prokaryotes however suggests that bacterial TIR domains mediate a broad spectrum of functions beyond interference with antimicrobial defenses of multicellular organisms. The signaling functions of TIR domains are due to their ability to mutually interact to form transitory oligomeric complexes that typically serve as platforms for recruitment of 
other signaling components (Kagan et al. 2014). These complexes can contain either additional interaction domains, such as the death domain within the adapter TIR protein MyD88, or a catalytic domain capable of transducing the signal spatially (Ferrao et al. 2012). TIR domain interactions involve distinct structural surfaces, thereby allowing multiple interactions simultaneously (Toshchakov et al. 2011).

A second recognized function, found in a subset of phylogenetically distant TIR domains, is enzymatic degradation of nicotinamide adenine dinucleotides (NAD) (Essuman et al. 2017, 2018; Horsefield et al. 2019; Wan et al. 2019). Although associated with TIR domains as phylogenetically distant as bacteria, plants, and animals, this function is not as common as their signaling function and often depends on or is regulated by either homo- or heteromeric TIR association (Essuman et al. 2018; Horsefield et al. 2019; Wan et al. 2019).

The consensus TIR domain consists of $5 \beta$-strands, which form a central parallel $\beta$-sheet, alternating with $5 \alpha$-helices, which surround the $\beta$-sheet (Rock et al. 1998; Xu et al. 2000). An early survey of 29 TIR-encoding genes identified three conserved TIR-specific sequence motifs, named Box 1, Box 2 , and Box 3 (Slack et al. 2000), corresponding to the first $\beta$ strand, the loop that connects the second strand and second helix, and the fifth helix, respectively. ${ }^{1}$ Later analyses, however, found that Boxes 2 and 3 are poorly conserved among diverse TIR domains (Ve et al. 2015).

Here we apply Bayesian partitioning with pattern selection (BPPS) (Neuwald 2014a, b) to classify the TIR domains based on those residue patterns that best distinguish each group from other, closely-related groups and that presumably correspond to group-specific functional determinants. To obtain biological insights, we contrast and compare such features among various subgroups in the light of available structures and of published studies. In particular, we compare TIR domains of Toll proteins of arthropods and Toll-like receptors of other metazoans with IL-1R family and plant TIRs. We also examine residue patterns characteristic of MyD88, TIRAP/Mal, and SARM1 proteins and consider the functional implications. Our survey reveals many group-specific structural variations and conserved surface patches that likely define group-specific interactions.

\section{Materials and methods}

\section{Database searches}

TIR domain sequences in the NCBI non-redundant (nr) and environmental (env_nr) protein sequence databases and from

\footnotetext{
${ }^{1}$ Strands and helices of the TIR domains are alphabetized starting from the Nterminus. Loops are indicated by two capital letters, according to the structural elements they connect. Thus, the BB loop is the loop that connects second $\beta$ strand with second helix, while the CD loop connects the third helix with the fourth strand.
}

the translated NCBI EST database (Agarwala et al. 2018) were identified and multiply aligned using MAPGAPS (Neuwald 2009). A curated multiple sequence alignment (MSA) of TIR domains (smart00255) from the SMART database (Letunic and Bork 2018) served as the initial MAPGAPS query. The TRIF and TRAM query MSAs were constructed manually. The identified TIR pool was refined by removal of sequence fragments (i.e., sequences that fail to match at least $75 \%$ of the columns in the query MSA) and all but one sequence among those sharing $\geq 98 \%$ identity. The refined MSA served as input to BPPS.

\section{BPPS classification}

BPPS was performed as previously described (Neuwald 2014a, b). BPPS identifies subgroup-specific sets of coconserved residues presumably associated with functional specialization. BPPS uses Markov chain Monte Carlo (MCMC) sampling to stochastically move sequences between hierarchically arranged partitions, each defined by an evolving characteristic pattern. Upon convergence, this defines subgroups and corresponding conserved patterns that best distinguish each subgroup from those further up the hierarchy. The benefit of BPPS over construction of a phylogenetic tree is identification of subgroup-specific residue patterns and the ability to analyze very large numbers of sequences; modeling thousands of sequences as a tree introduces more complexity than either is necessary or can be reliably inferred.

\section{Primary data presentation}

The primary data are presented in Supplemental Fig. 1, which presents a series of MSAs for each group of the hierarchy, and in Supplemental Fig. 2, which lists all of the sequences. The first line of each group-specific MSA shows the consensus sequence for the group, followed by representative sequences for each major phylum. The first MSA in each group-specific series shows major phyla represented in the group and the corresponding TIR sequence, for which all residues conserved in the subgroup are highlighted. The subsequent MSAs are "contrast alignments" highlighting those residues specifically conserved in the group (and subgroup) of interest. The three lines immediately below each contrast MSA show the most frequent residues at each position and below this their corresponding frequencies as integer tenths (for example, number 4 indicates the corresponding residue is present in $40-50 \%$ of the sequences). The lines that present the group-specific residues, referred to as "foreground residues," are followed by analogous presentation of "background" residues, i.e., parent group residues. The 25 most characteristic foreground residues (i.e., those most divergent from the background) are denoted by black dots above the alignments. The red bars above the dots are proportional to a measure of selective constraint, 
as defined by an urn model in which residues correspond to distinctly colored balls in an urn, and where some of the colors are similar (representing biochemically similar residues). The selective constraint is then defined as the expected number of random trials required to draw by chance at least as many of the same- or similarly colored balls from the background urn as are observed in the foreground. (The background for the root node consists of overall residue frequencies in proteins.) Because the associated probabilities vary over a wide range, a column with $p=0.01$ (100 trials) would disappear relative to a column with $p=0.00001$ (100,000 trials). To work around this problem, the BPPS program optimally adjusts (so as to span the full range of) bar heights using the formula $h=\frac{t^{1-\sigma}}{1-\sigma}$, where $t$ is the number of trials and $0 \leq \sigma<1$ is a scaling parameter that converges to linear scaling at $\sigma=0$ (for further details, see Neuwald et al. 2003). 3D images were generated using DeepView - Swiss-PdbViewer (Guex and Peitsch 1997).

\section{Results}

\section{Detection and classification of TIR domains (general description of identified groups)}

BPPS classified TIR domains into 36 groups, 6 of which were subdivided further into subgroups (Fig. 1a). Among these were 9271 bacterial, 6434 metazoan, 9522 higher plant, 118 archaeal, 292 protozoan, 16 chlorophytan, and 758 phylogenetically unclassified TIR domains (Fig. 1b). Twenty-two TIR groups predominantly contained prokaryotic proteins, whereas 13 exclusively comprised eukaryotic proteins. Only group 17 combines prokaryotic TIRs with a significant percentage of eukaryotic TIRs: $\sim 10 \%$ protozoan, $\sim 10 \%$ lower metazoan, and $\sim 1.5 \%$ plant TIR domains (Fig. 1c).

Of the 13 eukaryotic TIR groups, 3 are plant (Streptophyta) (Fig. 1c), 9 are metazoan, and one (group 18) is a combination of protozoan and metazoan TIRs (Fig. 1c). Most group 18 TIRs are from lower metazoans, including $24 \%$ from Cnidaria, $22 \%$ from mollusks, and $16 \%$ from echinoderms. Thirteen percent of group 18 TIRs are from evolutionally early chordates, such as lancelet and Ascidia, or from bony fish. Seven TIRs in this group are from green algae (chlorophytes). Group 18 is the only eukaryotic group that contains TIR proteins with diverse domain architectures, whereas all other eukaryotic groups represent either a single TIR-containing protein or a protein family (Fig. 1e).

There are 3 groups of Streptophyta TIRs, i.e., groups 2, 16, and 21 (Fig. 1c). Group 2 is the largest of all groups and contains several subgroups (Fig. 1a, c). Group 2 TIR proteins are large, cytoplasmic receptors that contain the TIR in tandem with a nucleotide-binding (NB) domain followed by multiple leucine-rich repeats (LRRs), whereas group 21 proteins lack a NB domain and LRRs, but contain another interaction domain and may contain a catalytic unit. Group 16 TIRs are often paired with an ATPase.

The phylogenetic composition of individual metazoan groups is shown in Fig. 1e. Three of 10 metazoan groups correspond to Toll-like receptors (TLRs) (Fig. 1e). The largest TLR group, i.e., group 3, combines Toll proteins of arthropods with TLRs of other metazoan lineages, but excludes endosomal TLRs (TLR7-9) and TLR11-13. TLR7-9 and TLR11-13 are associated with groups 7 and 29, respectively (Fig. 1e). TIRs of the IL-1R family are associated with group 4. SARM1 and TIRAP/Mal are associated with groups 24 and 10, respectively (Fig. 1e). MyD88 is associated with groups 23 and 32. Group 32 consists exclusively of arthropod TIRs, whereas group 23 consists of other metazoan TIRs. Interestingly, proteins of groups 23 and 32 have different domain architectures. Group 23 TIR proteins typically contain an N-terminal death domain followed by the TIR, whereas group 32 (arthropod) TIR proteins are typically larger and have a domain architecture similar to that of Drosophila MyD88 (Horng and Medzhitov 2001); all group 32 proteins examined here have a C-terminal localization domain, in addition to the death and TIR domain (Marek and Kagan 2012).

Unlike most eukaryotic groups, the majority of prokaryotic TIR groups are polyphyletic at the phylum level (Fig. 1g). However, more than $95 \%$ of group 6,13, and 26 TIRs are from Actinobacteria, and most group 11, 27, 30, and 31 TIRs are from Proteobacteria (Fig. 1g). Group 22 contains the largest percentage of archaeal genes (8\%). Group 12 contains the largest portion of TIRs from Firmicutes (41\%) (Fig. $1 \mathrm{~g})$.

\section{Sequence features generally conserved in TIR domains}

The residue patterns conserved among all TIR domains are highlighted in Fig. 2a and largely occur in regions corresponding to three $\beta$-strands (labeled $\beta \mathrm{A}, \beta \mathrm{C}$, and $\beta \mathrm{D}$ in Fig. $2 \mathrm{a}-\mathrm{c}$ ), which form the TIR domain inner core. The surface-exposed strands, i.e., $\beta \mathrm{B}$ and $\beta \mathrm{E}$, which form lateral edges of the $\beta$ sheet, are not conserved (Fig. 2b, c). Three pattern residue positions prior to $\beta C$ correspond to $\alpha$-helix B (Fig. 2a) with the two hydrophobic residues packing against $\beta$-strands in TLR2, MyD88, IL1RAPL1, and TcpB (PDB IDs: 1fyw, 4eo7, 1t3g, and 4lqc, respectively).

The conserved aromatic residue at the CC loop (position $66^{2}$ ) forms a structural element conserved in most TIR domains (Fig. 2d). The side chain of this residue is involved in intramolecular interactions with three conserved residues of

\footnotetext{
${ }^{2}$ Here and throughout the text, residues are numbered to correspond to multiple sequence alignments, not to individual protein sequences.
} 

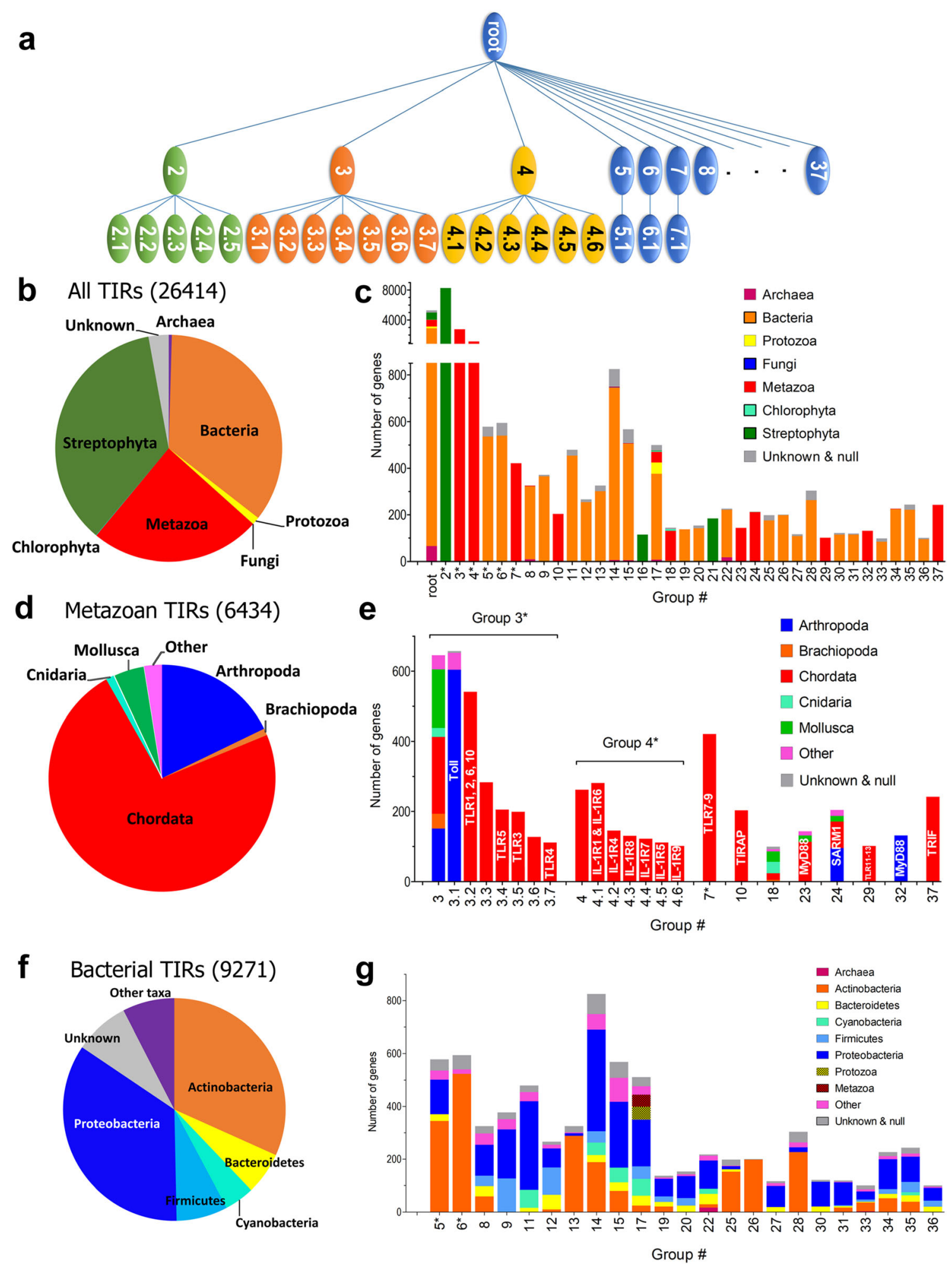

$\beta C$ (Fig. 2d), one of which is serine/threonine- 63 at the end of $\beta C$ (Fig. 2a, d). This serine/threonine forms two hydrogen bonds with the backbone nitrogen of the conserved tyrosine/ phenylalanine-66 (Fig. 2d). The other two interactions are through the aromatic side chain-66 and hydrophobic side chains of two core $\beta C$ residues at positions 60 and 62 (Fig. 2d). An apparent function of these residues is to stabilize the drastic turn of polypeptide backbone after $\beta \mathrm{C}$, thereby ensuring correct folding.

The glutamic acid-75 (E75) located between $\beta \mathrm{C}$ and $\beta \mathrm{D}$ is conserved in more than $70 \%$ of all TIR domains (Fig. 2a). This glutamic acid was found to be critically important for 
Fig. 1 Hierarchical classification and phylogenetic composition of BPPS-defined TIR domain groups. a Bayesian classification of TIR domains. b Phylogenetic composition of the analyzed pool of TIR domains. Plant, animal, and bacterial TIR domains are nearly equally represented. c Phylogenetic composition of individual groups. The partition has differentiated plant (green columns), animal (red), and bacterial (brown) TIR domains into separate groups. Only group 17 combines bacterial TIRs with a significant number of eukaryotic TIRs. d Phylogenetic composition of metazoan groups. e Phylogenetic composition of individual metazoan groups. Except for group 18, the metazoan groups represent a single protein or a protein family. Characterized protein subgroups are indicated on column. Group 18 combines TIRs from architecturally diverse protozoan and lower metazoan proteins. Taxa accounting for less than $3 \%$ of a group are grouped into "Other." $\mathbf{f}$ Phylogenetic composition of the analyzed pool of bacterial TIRs. g Phylogenetic composition of individual bacterial groups. Bacterial groups typically comprise proteins with diverse domain architecture. Phylogenetic composition of bacterial groups varies; there are, however, some common features. For example, cyanobacterial TIRs typically co-partition with proteobacterial TIRs

the NADase activity present in a subclass of bacterial, archaeal, and plant TIR domains, and in metazoan SARM1 (Essuman et al. 2017, 2018; Horsefield et al. 2019; Wan et al. 2019). We confirm the high frequency of E75 (>90\%) in TIR groups, for which the NADase activity has been reported, i.e., groups 2 (plant NB-LRR receptors) and 24 (SARM1 orthologs) (Supplemental Table 1). The E75 frequency, however, does not necessarily correlate with reported enzymatic activity. Thus, E75 is frequent (>90\%) in subgroup 3.2 (TIRs of TLRs that heterodimerize, i.e., TLR1, TLR2, TLR6, and TLR10), but is rare $(<10 \%)$ in endosomal TLRs, in TIRAP and in MyD88, i.e., groups 7, 10, and 23, respectively (Supplemental Table 1). The high global conservation of E75 suggests that this residue plays a role beyond catalysis. E75 is the only highly TIR-conserved residue with significant surface exposure; other TIR-conserved residues form a tightly packed core maintaining structural integrity (Fig. 2e). Surfaceexposed residues mediating intermolecular TIR-TIR interactions are likely to be subgroup-specific.

\section{TIR domains of green plants}

Plant TIR domains form three separate groups, i.e., 2, 16, and 21 (Fig. 1c), all from higher plants (Embryophyta) and each

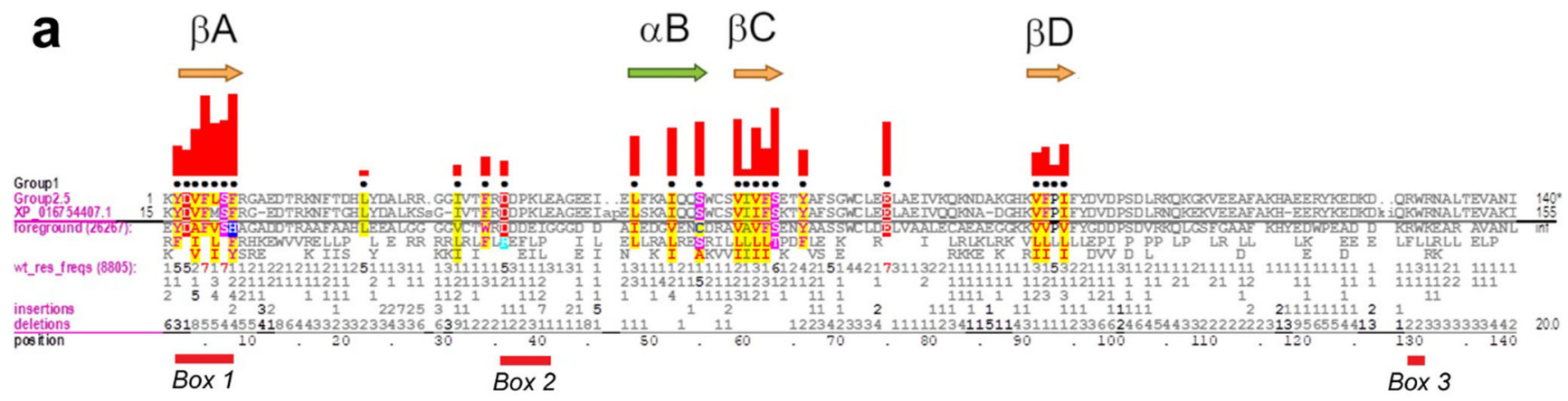

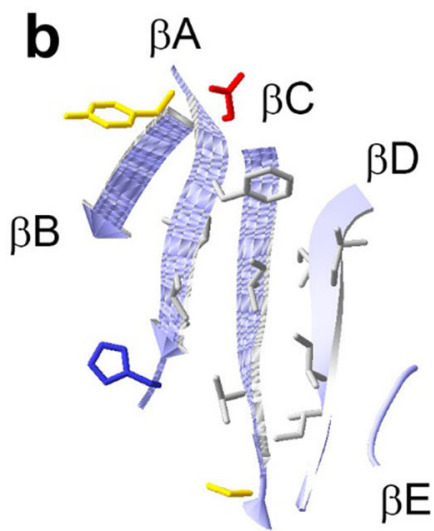

C

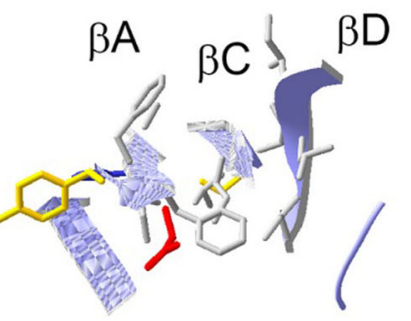

d

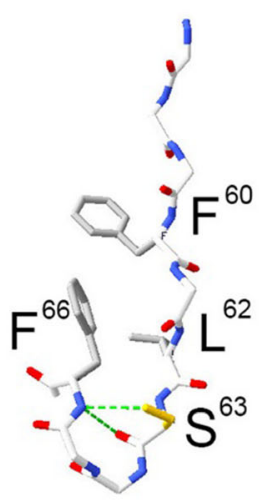

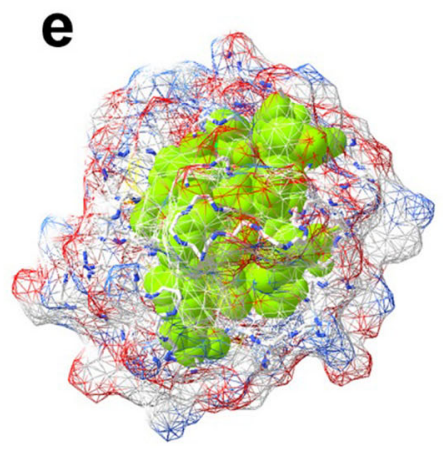

Fig. 2 Pattern residues and structural features characteristic of TIR domains. a TIR domain residue patterns. Pattern positions are indicated by black dots above the alignment with the heights of red bars indicating the selective constraint imposed at those positions (Neuwald et al. 2003). Arrows indicate selected secondary structural elements. Horizontal bars beneath alignment indicate three motifs, named Boxes 1-3, previously identified in a subset of TIRs (Slack et al. 2000). b, c The $\beta$-sheet of TcpB TIR domain in "front" (b) and "top" (c) view. Side chains are shown for conserved residues. Images correspond to coordinate file 4lqc (Snyder et al.

2014). d Interactions of the conserved tyrosine/phenylalanine at position 66 proposed to stabilize the $\mathrm{CC}$ loop conformation. The backbone nitrogen of F66 interacts with S63 through two hydrogen bonds. The F66 side chain interacts with conserved hydrophobic residues of $\beta C$. The image shows residues $698-707$ of TLR2 (PDB ID: 1FYW) (Xu et al. 2000). e Residues generally conserved in TIR domains form the tightly packed core of Hydra magnipapillata Tollrelated receptor-2 (TRR-2) TIR domain (PDB ID: 4W8H) (Weisse and Scheidig 2015). Conserved residues are shown in green in the space-filling mode 
associated with a characteristic protein domain architecture. Group 2 includes 5 subgroups and consists of 8258 domains (Fig. 1a, c). Nearly all proteins harboring a group 2 domain have the TIR located at their N-terminus, followed by a nucleotide-binding (NB) domain, and C-terminal LRRs. This domain architecture represents NB-LRR proteins, a large, polyphyletic class of intracellular receptors that, upon recognition of pathogen-associated molecules or effectors, activate cell death-inducing proteases (Dodds and Rathjen 2010; Urbach and Ausubel 2017). The large size of group 2 is due to the abundance of genes of this type in plant genomes (Van der Biezen and Jones 1998). Group 16, which consists of 114 TIR domains, occur in proteins lacking LRRs, but typically having a TIR preceded by 150-180 N-terminal residues and followed by a P-loop NTPase domain. Examination of domain architecture of group 21 proteins suggested these usually occur as single-domain adapter proteins, though some have a second interaction domain and a few have an amylase domain. Predominance of single-domain architecture in group 21 proteins suggests this group has evolved as adapters that facilitate recruitment of group 16 proteins to plant TIR-containing NBLRR proteins. Finally, there are also $\sim 1000$ unclassified green plant TIR domains assigned to the root (Fig. 1c).

These observations suggest that group 21 corresponds to signaling adapter proteins that act downstream of group 2 TIR-containing NB-LRR receptors and that facilitate recruitment of group 16 TIR-containing NTPases. The relatively large number of group 2 TIR proteins suggests that plant NB-LRR receptors use common downstream group 16 and 21 TIR signaling proteins. This notion is compatible with the general observation that different pathogens elicit significantly overlapping gene expression profiles in plants and animals (Boller and Felix 2009). Because BPPS, based solely on the TIR domain residue patterns, almost perfectly differentiates plant protein families with different domain architectures, the sequence features conserved in these groups are likely to be functionally important.

\section{Group 2: TIR domains of phytopathogen-sensing NB-LRR receptors}

The pattern residues characteristic of group 2 TIR domains (Fig. 3a) form several clusters, as shown in Fig. 3b-e

AA loop conserved residues Group 2-specific residues in the AA loop form a surface-exposed cluster (Fig. 3a, b), which includes both an $-\mathrm{F}_{9} \mathrm{R}_{8} \mathrm{G}_{9}$ - motif (subscript numbers indicate the frequency of occurrence in tenth parts) and $\mathrm{R} 15_{8}$ and which forms part of the ligand-binding pocket of the NADcleaving NB-LRR protein, RUN1 (black bars in Fig. 3a indicate pocket residues). The lack of conservation among residues corresponding to the ligand-binding pocket of RUN1 (such as those within the BB loop) is consistent with some plant-derived TIRs being incapable of cleaving NAD (Horsefield et al. 2019) and with plant NB-LRR receptors utilizing multiple signaling mechanisms (Wan et al. 2019).

Hydrophobic residues in the $\mathrm{aC}$ region The side chains of conserved group 2 residues between $\beta$-strands $\mathrm{C}$ and $\mathrm{D}$ (Fig. 3a) interact with the TIR core and are less than $5 \%$ surface exposed (Fig. 3d).

Antiparallel, hairpin-like $\alpha$-helical structure between $\beta D$ and $\beta E$ The largest cluster of group 2 residues occurs near the junction of the $\beta \mathrm{D}$ - and $\beta \mathrm{E}$-strands with a hairpin-like structure of three $\alpha$-helices (denoted $\alpha \mathrm{D}^{\prime}, \alpha \mathrm{D}^{\prime \prime}$, and $\alpha \mathrm{D}^{\prime \prime \prime}$ ) that is oriented perpendicular to the $\beta$-strands (Chan et al. 2010) (Fig. 3e). All available group 2 TIR domain structures conserve this structural arrangement (Fig. 4a), which appears to uniquely characterize this group; in other groups, this forth helical region typically consists of one or two helices of varying length and orientation in relation to $\beta$-strands (Fig. $4 \mathrm{~b}-\mathrm{h}$ ).

\section{Groups 16 and 21: plant TIR domains}

The structures of group 16 and 21 TIR domains are currently unknown. Group 16 TIRs are characterized by the presence of a conserved G7 in $\beta$-strand $A$, rather than the Ser present at this position in $>70 \%$ of all TIRs (Supplemental Fig. 1). Other group 16-specific residues are W21 $(\alpha \mathrm{A})$ and C33 ( $\beta \mathrm{B})$ (Supplemental Fig. 1). Box 2 is not conserved in group 16; although W130 of Box 3 is conserved, it is typically flanked by 3 polar residues, which rarely occurs in other TIRs. Group 21 characteristics include as follows: a $\mathrm{C} 67$ at the start of $\alpha \mathrm{C}$, followed by a groupspecific highly conserved $\alpha \mathrm{C}$ segment; a -Pro-Gly- pair in the Cterminal half of the $\mathrm{BB}$ loop; and a conserved $\alpha \mathrm{E}$ region distinct from other TIRs (Supplemental Fig. 1).

\section{Toll and Toll-like receptor TIR domains}

Arthropod Toll proteins and Toll-like receptors (TLRs) of other metazoans form groups 3, 7, and 29. With few exceptions, proteins in these groups are single-span transmembrane receptors consisting of N-terminal LRRs, a transmembrane helix, and a cytoplasmic TIR domain (Medzhitov et al. 1997; Rock et al. 1998). Group 3 is the largest group of metazoan TIR domains, represented here by 2763 sequences (Fig. 1c). Like group 2, the largest group of plant TIR domains, group 3 represents a family of (germline) receptors that detect pathogens. Most group 3 proteins are from insects and vertebrates, though they are also present in lower protostomes and deuterostomes, but not in sponges or flatworms (Gauthier et al. 2010; Nie et al. 2018; Wiens et al. 2007) (Supplemental Fig. 2)-suggesting group 3-specific features emerged during early evolution of metazoan body plans. 


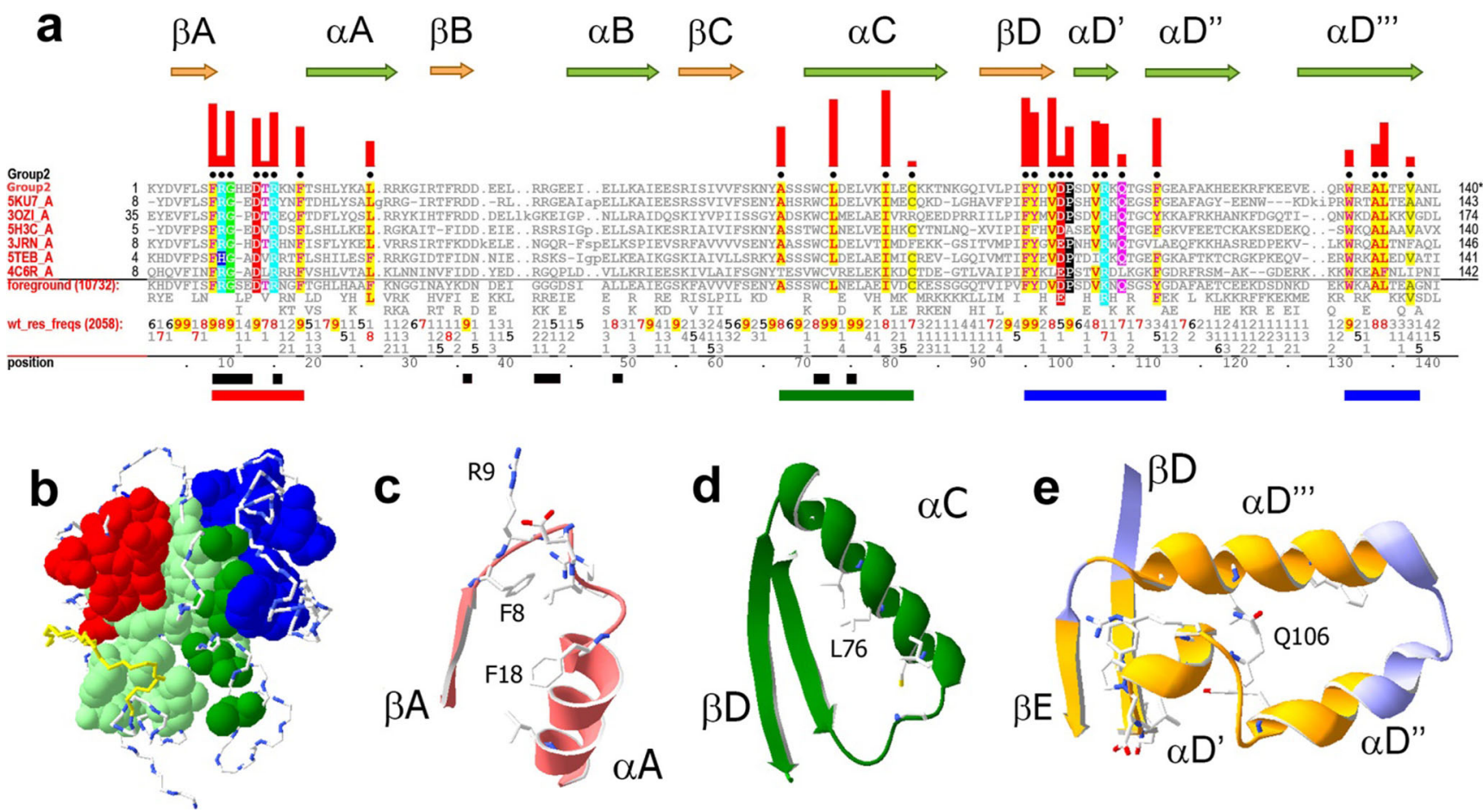

Fig. 3 Group 2-specific residues and structural features. a Group 2 residue patterns. Formatting is as for Fig. 2a. Arrows above the alignment indicate secondary structure elements. Black bars directly below the alignment indicate residue positions forming the NADPbinding pocket of Vitis rotundifolia RUN1 NB-LRR receptor (PDB ID: 6O0W) (Horsefield et al. 2019). The colored horizontal bars beneath the alignment show clusters of pattern residues shown in same color in panel b. b Group 2-specific residue clusters in relation to residues conserved in all TIR domains for the grape RUN1 protein (PDB ID: 6O0W). Conserved residues and the backbone of non-conserved residues are shown in space-filling and stick modes, respectively. Group 2-specific residues of the AA loop, of $\alpha \mathrm{C}$, and of the $\alpha \mathrm{Ds}$ are colored red, dark

Group 7 and 29 TIRs are present only among chordates (Fig. 1c). Group 7 includes TIRs of TLR7, TLR8, and TLR9, which are endosomal TLRs that sense viral single-stranded RNA and bacterial CpG motif-enriched DNA. Group 29 TIRs are related to TLR11, TLR12, and TLR13. This group has a patchy distribution among chordates. For example, TLR11-13 are functional in many rodents and ungulates, whereas many distantly related species (such as humans and dogs) have a pseudogene at the syntenic position (Roach et al. 2005).

\section{Group 3: Toll proteins and plasma membrane TLRs (TLR1-6 and TLR10s)}

Group 3 subgroups Group 3 TIRs are subdivided into 7 subgroups (Fig. 1a, e). Subgroup 3.1 is the largest (652 invertebrate TIRs) (Fig. 1e) and includes 604 arthropod Toll proteins along with representatives from 9 other phyla, i.e., Mollusca, Cnidaria, Echinodermata, Brachiopoda, Annelida, Priapulida, Tardigrada, and Chordata - though all 14 chordate proteins are from lancelets, which are primitive chordates. Subgroup green, and blue, respectively (i.e., as the horizontal colored bars in panel a); residues conserved among all TIR domains are colored light green. c Group 2-specific residues in the AA loop region of the grape Rpv1 protein (PDB ID: 5ku7) (Williams et al. 2016) and corresponding to the red cluster in panel $\mathbf{b}$. $\mathbf{d}$ Conserved group 2 residues in the $\alpha \mathrm{C}$ region, which contact core $\beta$-strands and helices $\alpha \mathrm{D}^{\prime \prime}$ and $\alpha \mathrm{D}^{\prime \prime \prime}(\alpha \mathrm{Ds}$ are shown separately in panel e) (PDB ID: 3ozi; Bernoux et al. 2011). e The group 2 -specific residues between $\beta \mathrm{D}$ and $\beta \mathrm{E}$. This region comprises three $\alpha \mathrm{D}$ helices that together form a hairpin-like structure oriented perpendicularly to $\beta$-strands. Sidechains of group 2 residues at the three-helix structural interface are shown. Highlighted in yellow are residues in van der Waals contacts with conserved residues

3.2 includes TLR2 and TLRs, which heterodimerize with TLR2, i.e., TLR1, TLR6, and TLR10 (Fig. 1e). Subgroup 3.3 TIRs are absent in mammals, but present in TLRs of cold-blooded vertebrates and birds. TLR3-, TLR4-, and TLR5-related TIR domains form subgroups 3.5, 3.7, and 3.4, respectively (Fig. 1e). As for group 3.3, group 3.6 TIRs are present in vertebrates, excluding mammals.

Group 3 proteins with atypical domain architectures Only a few group 3 TIR proteins have a domain architecture different from that of Toll proteins and TLRs. Such atypical proteins are well documented for cnidarians; for example, in several actiniarian TIR proteins, Ig-like domains replace LRRs (van der Burg et al. 2016) and in Hydra magnipapillata, a membrane-anchored TIR protein lacks a ligand-binding domain (Bosch et al. 2009).

Group 3 TIR domain residue patterns and structural features Group 3-specific residue clusters (Fig. 5a) and their structural locations (Fig. 5b-e) differ from those of group 2. Two largest 

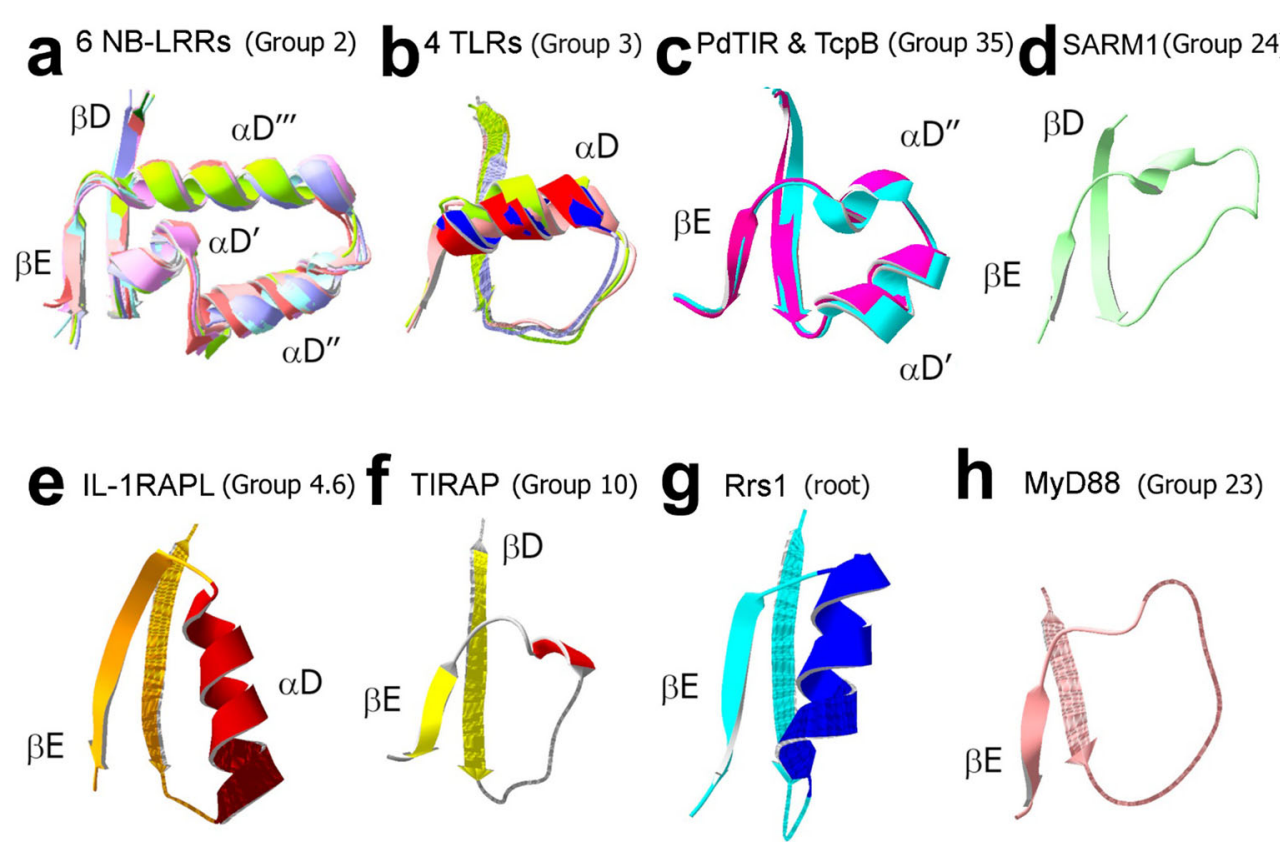

DyD88 (Group 23)

Fig. 4 The fourth helical region of TIR domains differ among, but are highly similar within different groups. Shown are the $\beta \mathrm{D}-$ and $\beta \mathrm{E}$ strands, together with the connecting segment, for TIR domains of different groups. Within each group, the region between $\beta \mathrm{D}$ and $\beta \mathrm{E}$ is nearly identically folded across multiple 3D structures, i.e., for groups 2,3 (subgroup 3.2), and 35 (panels a-c), whereas across groups, this region differs drastically (panels $\mathrm{a}-\mathrm{h}$ ). a Region between $\beta \mathrm{D}$ and $\beta \mathrm{E}$ superimposed across six structures of group 2 TIRs: flax disease resistance protein L6 (Linum usitatissimum) (PDB ID: 3ozi) (Bernoux et al. 2011), NP_177436 protein from Arabidopsis thaliana (PDB ID 3jrn) (Chan et al. 2010), Arabidopsis thaliana suppressor of Npr1-1, constitutive 1 (SNC1) (PDB ID: 5h3c) (Hyun et al. 2016), RPS4, and RPP1 (PDB IDs: 4c6t) (Williams et al. 2014) and 5teb (Zhang et al. 2017), and grape RPV1 protein (PDB ID: 5ku7) (Williams et al. 2016).

b Superimposed group 3.2 (TLRs which heterodimerize: TLR1, TLR2, TLR6, and TLR10) TIR regions corresponding to the region shown in panel a (PDB IDs: 1fyv, 1fyw, 4om7, and 2j67). c Superimposed regions for the bacterial group 35 TIRs: PdTIR from Paracoccus denitrificans (PDB ID: 3h16) (Chan et al. 2009) and TcpB from Brucella abortus (PDB ID: 4lqc) (Snyder et al. 2014). d Corresponding region for group 24 TIR (hSARM1, PDB ID: 6O0Q) (Horsefield et al. 2019). e Corresponding region for group 4 TIR IL-1R accessory protein-like (IL-1RAPL), also known as IL-1R9 (PDB ID: 1t3g) (Khan et al. 2004). fCorresponding region for TIRAP (PDB ID: 4lqd) (Snyder et al. 2014). $g$ Corresponding region for Rrs1, a plant TIR assigned to the root (PDB ID: 4c6t) (Williams et al. 2014). h Corresponding region for group 23 TIR MyD88 (PDB ID: 2js7)

clusters (highlighted by red and purple in Fig. 5b) are located at opposite TIR surfaces near $\beta$-strands, which form the lateral edges of the $\beta$-sheet, i.e., strands $\beta \mathrm{B}$ and $\beta \mathrm{E}$ (Fig. 5a, b). These clusters correspond to two out of four sites that mediate assembly of TLR complexes and initiation of intracellular signaling (Javmen et al. 2018; Toshchakov and Javmen 2020; Ve et al. 2017). The TIR sites near $\beta B$ and $\beta E$ mediate TLR TIR dimerization and lateral extension of the initial complex through recruitment of adapter TIRs. Many group 3 TLR residues are within these interaction sites; these conserved features are discussed below in more detail.

Cluster of conserved residues near $\beta$ B (extended Box 2) The largest group 3-specific cluster includes 7 conserved residues near $\beta B$ that form the motif: $-\mathrm{E}_{8}-\mathrm{x}-(\mathrm{x}-\mathrm{x})-\mathrm{x}[5]-\mathrm{C}_{9}-\mathrm{x}-\mathrm{H}_{6}-\mathrm{x}-\mathrm{R}_{9}-$ $\mathrm{D}_{8}-\mathrm{F}_{7}-\mathrm{x}-\mathrm{x}-\mathrm{G}_{9^{-}}$(Fig. 5a, c). This cluster corresponds to the red bar below the Fig. 5a alignment. The first residue of this motif, $\mathrm{E} 23$, is at the C-terminal end of $\alpha \mathrm{A}$, followed by a variable $\mathrm{AB}$ loop region. $\mathrm{E} 23$ is present in more than $80 \%$ of group 3 TIRs, while another $\sim 10 \%$ have aspartic acid at this position (Fig. 5a). The three charged residues of the motif, i.e., E23,

R36, and D37, can form two salt bridges, where R36 interacts with both acidic residues, thereby creating an atomic layer that covers the edge-forming strand of the $\beta$-sheet (Fig. 5c), which may prevent non-specific interactions with other $\beta$-sheet proteins (Richardson and Richardson 2002).

$\mathrm{C} 32$ in the $\beta \mathrm{B}$ is buried in available structures of group 3 TIRs, i.e., of human TLR1, TLR2, TLR6, and TLR10 TIRs. In TLR1 and TLR6 (PDB IDs: 1FYV and 4OM7), this cysteine forms a disulfide bond with $\mathrm{C} 51$ situated at the buried side of $\beta B$ (not shown). The TLR2 and TLR10 TIRs lack C51, which is replaced by a serine or phenylalanine residue that contacts C32 (PDB IDs: 1FYW and 4J67). The group 3 BB loop pattern residues (-H-x-R-D-F-X-X-G-) have a high surface exposure and backbone torsion angles that vary significantly among available TIR structures, indicating that this region is conformationally flexible.

The BB loop region of TLRs has long been defined as Box 2, one of three TIR domain conserved regions (Slack et al. 2000) (Fig. 2a). This survey, which analyzes $\sim 500$ times more sequences than the initial survey, identifies additional TLRspecific conserved positions near Box 2, including the acidic 
residue at the $\mathrm{C}$-terminal end of $\alpha \mathrm{A}, \mathrm{F} 38$ of the $\mathrm{BB}$ loop, and $\mathrm{C} 32$ of $\beta \mathrm{B}$.

Cluster of aromatic residues near $\beta E$ (extended Box 3 ) The short $\beta E$-strand is a conserved feature of group 3 TIR domains that forms one edge of the $\beta$-sheet; it contains two group 3 residues and is preceded by the group 3 residue Y118 (Fig. $5 \mathrm{a})$. The most frequent variant of the $\beta \mathrm{E}$ motif is $-\mathrm{Y}_{7}-\mathrm{I} / \mathrm{L}_{8}-\mathrm{X}-$ $\mathrm{W}_{8^{-}} \mathrm{P}_{5^{-}}$(Fig. 5a). These $\beta$ E motif residues, unlike those of the $\beta \mathrm{B}$ motif, have minimal surface exposure and therefore seem unlikely to mediate intermolecular interactions. The I/L119 and W121 side chains are on the side of $\beta$-sheet facing helices A and $\mathrm{E}$ (Fig. 5d). W121 contacts group 3 residues W/F13 of $\alpha \mathrm{A}$, and $\mathrm{F} 129$ and $\mathrm{W} 130$ of $\alpha \mathrm{E}$, whereas $\mathrm{W} / \mathrm{F} 13$ also contacts W130 (Fig. 5d); these are distantly located in the primary sequence of TIR domains but interact in the 3D structure, suggesting a role in maintaining structural integrity. Two of these 4 residues, F129 and W130, constitute Box 3 (Slack et al. 2000). Hence, our findings clarify the functional significance of Box 3 , as it is a part of a larger set of aromatic residues mediating intramolecular contacts involving helices A and $\mathrm{E}$.
Conserved residues in the region between $\beta$-strands $D$ and $E$ Two $\alpha \mathrm{D}$ (positions 110 and 114) and one DD loop (position 99) hydrophobic residues (Fig. 5a, e) form another group 3-specific cluster. The region containing this cluster (blue bar in Fig. 5a) forms the group 3-specific fold variant of the fourth helical region (Figs. 4b and 5e), homologous to the hairpin structure of group 2 TIRs, shown in Figs. 3e and 4a. In both groups, the conserved residues contact the core residues of the $\beta$-sheet and apparently determine the fold of the $\alpha \mathrm{D}$ region and its orientation in relation to the $\beta$-sheet, distinct from that in other groups (Fig. 4). The side-chain and backbone conformation for residues 99, 110, and 114 are remarkably well conserved for all four group 3 proteins of known 3D structure (Fig. 5e).

\section{Group 7: endosomal, nucleic acid-sensing TLRs}

The most prominent feature of group 7 TIR domains, which include TLR7, TLR8, and TLR9, is a $>90 \%$ conserved pattern in the $\mathrm{N}$-terminal half of the BB loop, $\mathrm{E}_{9} \mathrm{E}_{9} \mathrm{R}_{9} \mathrm{D}_{9} \mathrm{~W}_{9} \mathrm{XP}_{9} \mathrm{G}_{9^{-}}$, with the glutamate and tryptophan residues being the most distinguishing feature (Supplemental

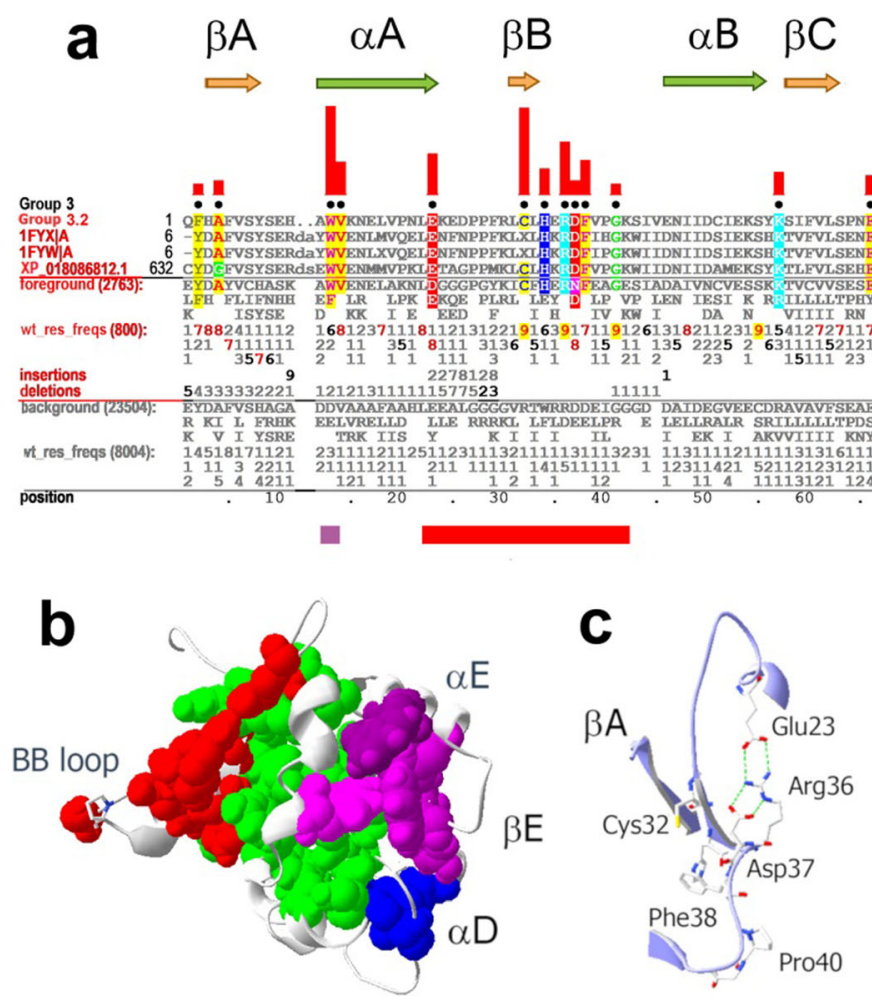

Fig. 5 Residue patterns and structural features associated with Toll protein and Toll-like receptor TIR domains. a Group 3-specific TIR domain residue patterns. Red, purple, and blue bars correspond to the similarly colored clusters in panel b. b The $\beta$ B, W/F13-V14/ $\beta \mathrm{E}$, and $\mathrm{DD}-\mathrm{loop} / \alpha \mathrm{D}$ group 3 residue clusters shown in red, purple, and blue, respectively, for TLR2 TIR domain (PDB ID: 1FYW). Residue positions conserved in all TIR domains are light green. c Side chains of group 3 residues clustered near $\beta$ B. R36 forms a salt bridge with E23 and with D37. The $\beta$ A-strand is shown to reveal
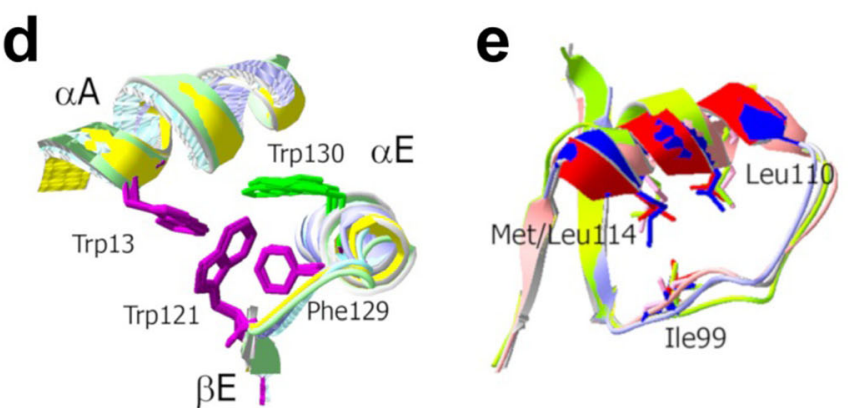

orientation relative to the $\beta$-sheet. d The W/F13-V14/ $\beta$ E cluster consisting of W121 of $\beta \mathrm{E}, \mathrm{F} 129$ and $\mathrm{W} 130$ of $\alpha \mathrm{E}$, and $\mathrm{W} 13$ of $\alpha \mathrm{A}$. To reveal the similar side-chain orientations of group 3 residues, the backbone atoms of $\alpha \mathrm{A}, \beta \mathrm{E}$, the $\mathrm{EE}$ loop, and $\alpha \mathrm{E}$ are superimposed for all four currently available structures: TLR1 (PDB ID: 1FYV) (Xu et al. 2000), TLR2 (PDB ID: 1FYW) (Xu et al. 2000), TLR6 (PDB ID: 4OM7) (Jang and Park 2014), and TLR10 (PDB ID: 2J67) (Nyman et al. 2008). e Three buried hydrophobic group 3 residues in the $\alpha \mathrm{D}$ region 
Fig. 1). Cell-permeable decoy peptides, which included either a large segment of this region or the entire motif, potently inhibited TLR9 signaling in cultured macrophages and in mice (Javmen et al. 2018). Another highly group 7-specific residue is $\mathrm{D} 9$ at the $\mathrm{C}$-terminal end of $\beta \mathrm{A}$. Group $7 \mathrm{TIRs}$ also conserve characteristic $\alpha \mathrm{C}$ and $\alpha \mathrm{D}$ motifs (Supplemental Fig. 1). However, a lack of structural data hinders functional interpretations.

\section{Group 29: TLR11-13}

The most prominent features of group 29 are $\mathrm{C} 61$ in $\beta \mathrm{C}$ and a highly conserved residue cluster between $\beta \mathrm{D}$ and $\beta \mathrm{E}$ (residues 98-115) (Supplemental Fig. 1), which suggests yet another $\alpha \mathrm{D}$ conformation variant among those shown in Fig. 4.

\section{TIR domains of cytokine receptors}

Group 4 TIRs, the third largest eukaryotic group (2203 sequences; Fig. 1c), correspond to the IL-1R family of cytokine receptors (Boraschi and Tagliabue 2013; Garlanda et al. 2013). In humans, all 10 of these TIR proteins contain a single transmembrane helix, a cytosolic TIR, and one or three extracellular Ig-like domains. The IL-1R family members function as heterodimers that recognize cytokines IL-1s, IL-18, IL-33, and IL-36s and activate downstream signaling molecules, many of which can also be activated by TLRs (Boraschi and Tagliabue 2013).

\section{Group 4 subgroups}

Group 4 includes six offspring subgroups (4.1-4.6), each of which includes characterized members of the IL-1R family (Fig. 1a). Members of subgroup 4.1, which is the largest in our analysis (281 sequences), correspond to TIRs within the main subunits of IL-1 or IL-36 receptors, namely IL-1R1 and IL-1R6, respectively (Garlanda et al. 2013). Subgroup 4.2 includes 145 TIR domains related to the IL-33 receptor IL1R4 (Fig. 1e), also known as ST2 (Boraschi and Tagliabue 2013; Garlanda et al. 2013). Subgroup 4.3 includes SIGIRR (single Ig and TIR domain containing), an orphan IL-1R family receptor, also known as IL-1R8 (Garlanda et al. 2013). Subgroups 4.4 and 4.5 correspond to TIRs in IL-18R's main and auxiliary subunits: IL-1R7 and IL-1R5, respectively. Subgroup 4.6 TIRs are related to IL-1R9, an orphan receptor also known as IL-1RAPL (Boraschi and Tagliabue 2013), and includes the only group 4 TIR of known structure, human IL1R9 (PDB ID: 1T3G) (Khan et al. 2004).

\section{Evolutionary distribution of group 4 TIRs}

As previously noted for IL-1R family (Buchmann 2014; Venkatesh et al. 2014; Wang and Secombes 2013), we find that all group 4 TIR domains occur in jawed vertebrates, but not in jawless fishes and lancelets. The elephant shark genome, which is reported to be the slowest evolving genome of any vertebrate, encodes (at least) 7 IL-1R family members, all belonging to group 4 (Supplemental Fig. 2; Venkatesh et al. 2014). This phylogenetic distribution pattern suggests that the group 4-specific traits arose simultaneously with IL-1R family and many other novel immune molecules in a series of macroevolutionary events, which followed two rounds of whole genome duplication, leading to the emergence of the adaptive immunity in jawed vertebrates (Flajnik and Kasahara 2010). Cnidarians appear to have multiple proteins with IL1R-like domain architectures (van der Burg et al. 2016), but our analysis assigned these to group 3 (Supplemental Fig. 2). Thus, the similarity of cnidarian IL-1R-like proteins and IL$1 \mathrm{R}$ family members appears due to convergent evolution.

\section{Group 4 residue patterns and structural features}

In addition to the three TIR domain conserved boxes described by Slack et al. (Slack et al. 2000), group 4 TIRs conserve several group-specific motifs.

Conserved $a \mathrm{~A}-\mathrm{aE}$ contacts through four aromatic residues (extended Box 3) More than 90\% of group 4 TIRs conserve the Box 3 aromatic residues F129 and W130 (Fig. 6a), which contact the conserved W121 at the C-terminal end of $\beta \mathrm{E}$ and F14 in $\alpha \mathrm{A}$ (Fig. 6c) - as is seen for the homologous group 3 cluster (Fig. $5 \mathrm{~d}$ ), except that the W121 aromatic ring is turned by $\sim 180^{\circ}$.

AB loop, $\beta$-strand $B$, and BB loop (extended Box 2 ) The cluster of residues conserved near $\beta \mathrm{B}$ in group $3\left(-\mathrm{E}_{8^{-}} \mathrm{x}(8)-\mathrm{C}_{9}-\mathrm{x}-\mathrm{H}_{6^{-}}\right.$ $\left.\mathrm{x}-\mathrm{R}_{9}-\mathrm{D}_{8}-\mathrm{F}_{7^{-}} \mathrm{x}-\mathrm{x}-\mathrm{G}_{9^{-}}\right)$is partly conserved in group 4 (- $\mathrm{E}_{9}-\mathrm{x}(3)-$ $\mathrm{G}_{9}-\mathrm{Y}_{9^{-}} \mathrm{x}-\mathrm{L}_{9}-\mathrm{x}-\mathrm{I}_{7}-\mathrm{x}-\mathrm{x}-\mathrm{R}_{9}-\mathrm{D}_{9}-\mathrm{x}-\mathrm{x}-\mathrm{P}_{9^{-}} \mathrm{G}_{8^{-}}$), as they share 4 out of 7 residues. In both cases, all 3 charged residues interact with each other in a similar manner, with nearly identical backbone folds for the entire region (compare Fig. 6d with Fig. $5 \mathrm{c}$ ). The most notable difference is the presence of a conserved -G28-Y29- pair in the AB loop of group 4 TIRs (Fig. 6a). The side chain of Y29 interacts with group 4-specific M138 at the C-terminal end of $\alpha \mathrm{E}$.

The $\beta E$-strand is atypically long and solvent-exposed: conserved polar or charged residues near $\beta E$ In the only known group 4 TIR structure, IL-1RAPL (PDB ID: 1T3G) (Khan et al. 2004), $\alpha \mathrm{D}$ is long and parallel to the $\beta$-strands and differs from that of other metazoan TIRs of known structure (Fig. 4e). $\beta E$ is similarly elongated (to 7 residues, compared with 3 residues in group 3 TIRs) (Fig. 4e) and forms a significant surface patch (Fig. 6e). This feature is contrary to the general tendency that, in globular domains, strands which form $\beta$-sheet edges are short and buried (Richardson and Richardson 2002), suggesting a possibility of the edge-to-edge type interaction of group 4 TIRs with other $\beta$-sheet proteins. However, group 4 fails to 


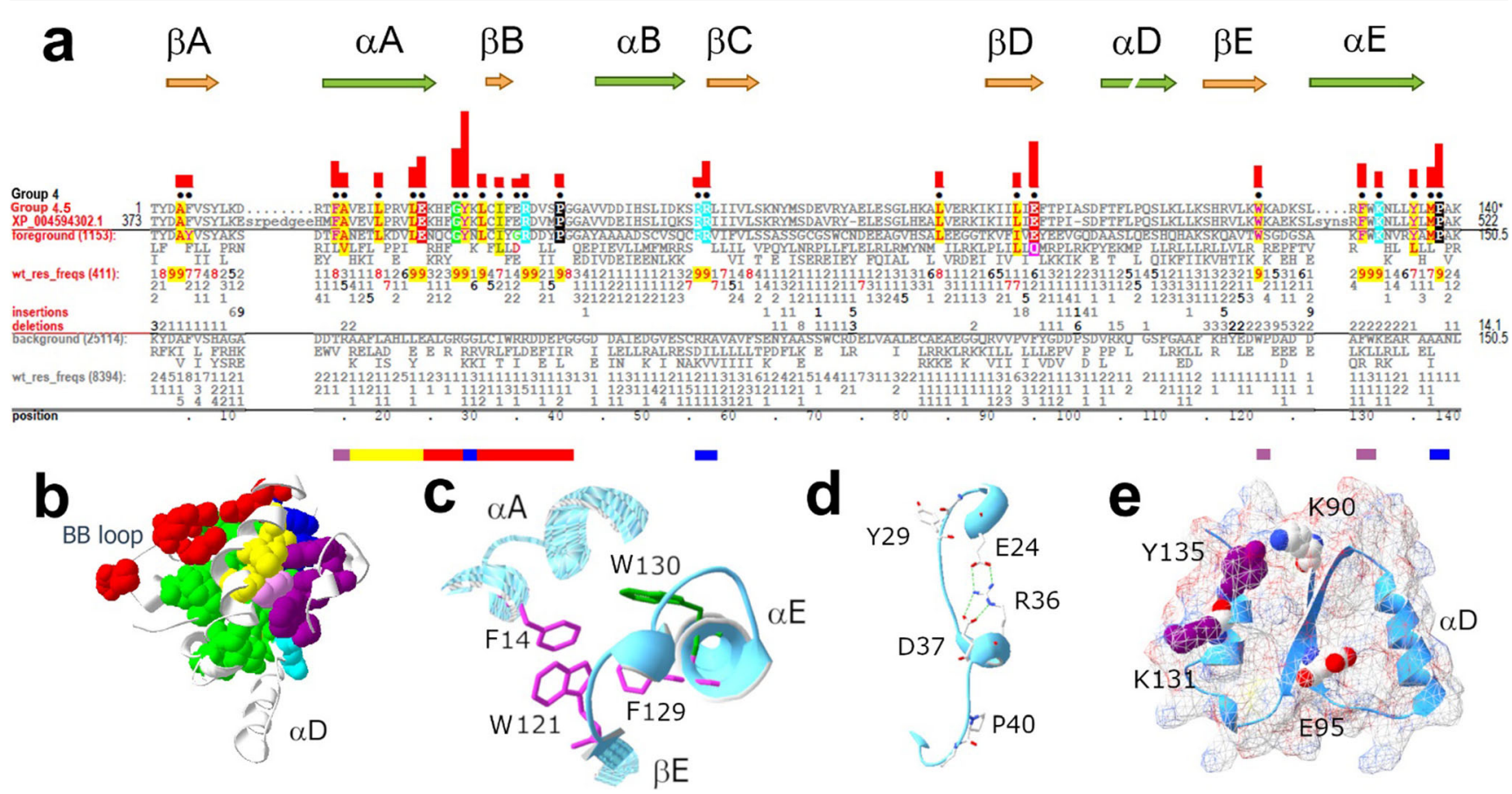

Fig. 6 Group 4 (IL-1R family) TIR domain sequence and structural features. a IL-1R family TIR domain conserved residue patterns. Bars below alignments correspond to structurally interacting regions colored to correspond to the clusters of mutually interacting residues shown in panel b. b Four 3D clusters of group 4-specific residues with side chains shown in red (the $\beta B$ cluster), purple (the $\beta E$ cluster, including F14), yellow (the hydrophobic side of $\alpha \mathrm{A}$ ), and blue for the IL-1R9 TIR domain (PDB ID: 1T3G) (Khan et al. 2004). Residues conserved in all TIR domains are

conserve residues in the $\alpha \mathrm{D}$ region (Fig. 6a), suggesting that other IL-1R family members may not share IL-1RAPL unusually shaped $\alpha \mathrm{D}$ and $\beta \mathrm{E}$ regions.

In addition to the extended backbone of $\beta \mathrm{E}$, the regional surface features include several conserved charged residues. Two of these (most frequently K90 and E95) are located at the ends of $\beta D$ (Fig. 6e). This pair is conserved in $>90 \%$ of subgroup 4.1, 4.2, 4.5, and 4.6 TIRs, whereas subgroup 4.4 (the TIR of the main subunit of IL-18R) has leucine in both positions and subgroup 4.3 (the TIRs of SIGIRRs) lacks this $\beta D$ feature (Supplemental Fig. 1). Two other surface-exposed conserved residues near $\beta E$ are K131 and Y135 of $\alpha \mathrm{E}$ (Fig. $6 \mathrm{e}$ ), which are present in $>90 \%$ and $70 \%$ of group 4 TIRs, respectively (Fig. 6a).

Conserved contacts at the aE C-terminus Group 4 TIRs conserve two buried residues at the $\alpha \mathrm{E}$ C-terminus, M137 and P138, which contact Y29 of the AB loop and two positively charged residues (positions 56 and 57) at the $\beta \mathrm{C} \mathrm{N}$-terminus, respectively (Fig. 6a, b).

\section{TIR domains of SARM1 orthologs (group 24)}

Group 24 includes SARM1 TIRs (Supplemental Fig. 2). These proteins harbor multiple Sterile $\alpha$ motifs (SAM) or colored light green. c A conserved cluster of four group 4 aromatic residues in the IL-1R9 TIR. This cluster, which is similar to the analogous group 3 cluster, includes F129 and W130 of Box 3, W121 at the C-terminus of $\beta \mathrm{E}$, and $\mathrm{F} 14$ in $\alpha \mathrm{A}$. d Group 4-specific cluster of conserved residues near the $\beta \mathrm{B}$-strand and homologous to the group 3 cluster that, as shown in Fig. 5c, also conserves both the three charged residues and the proline-glycine pair of the BB loop (see Fig. 5a). e Conserved structural features in the vicinity of $\beta E$

Armadillo (Arm) repeats or both, along with a C-terminal TIR (Mink et al. 2001; O'Neill et al. 2003). Group 24 TIRs occur among diverse metazoans (Fig. 7a), with typically one SARM1-like protein per genome (Fig. 1e).

Among metazoan TIRs, only SARM1 TIRs have known NADase activity (Essuman et al. 2017, 2018; Horsefield et al. 2019), which many bacterial and plant TIRs possess. SARM1's catalytic activity mediates neuron-specific programmed cell death in response to axonal injury due to mechanical or chemical trauma (Gerdts et al. 2013; Osterloh et al. 2012). It was proposed that metazoans acquired these TIRs from bacteria through multiple lateral gene transfers (Zhang et al. 2011), though our analysis fails to find bacterial SARM1 homologs. A crystal structure of human SARM1 reveals the ligandbinding pocket and catalytic site (Horsefield et al. 2019).

\section{Group 24 residue patterns and structural features}

Conservation of Box 1 Group 24 TIR domains have a moderately conserved Box 1 with a consensus $\left(-\mathrm{P}_{6} \mathrm{D}_{9} \mathrm{~V}_{9} \mathrm{~F}_{9} \mathrm{I}_{6} \mathrm{~S}_{9} \mathrm{Y}_{9^{-}}\right)$ that differs from the global consensus (-Y-D-V-F-I-S-Y-) only by the $\mathrm{N}$-terminal residue (Fig. 7a).

The BB loop region Group 24 conserves the BB loop region (typically as $\mathrm{E}_{8}(\mathrm{R} / \mathrm{K})_{9} \mathrm{~L}_{9} \mathrm{E}_{7} \mathrm{~A}_{9} \mathrm{G}_{9^{-}}$) (Fig. 7a), but not the 


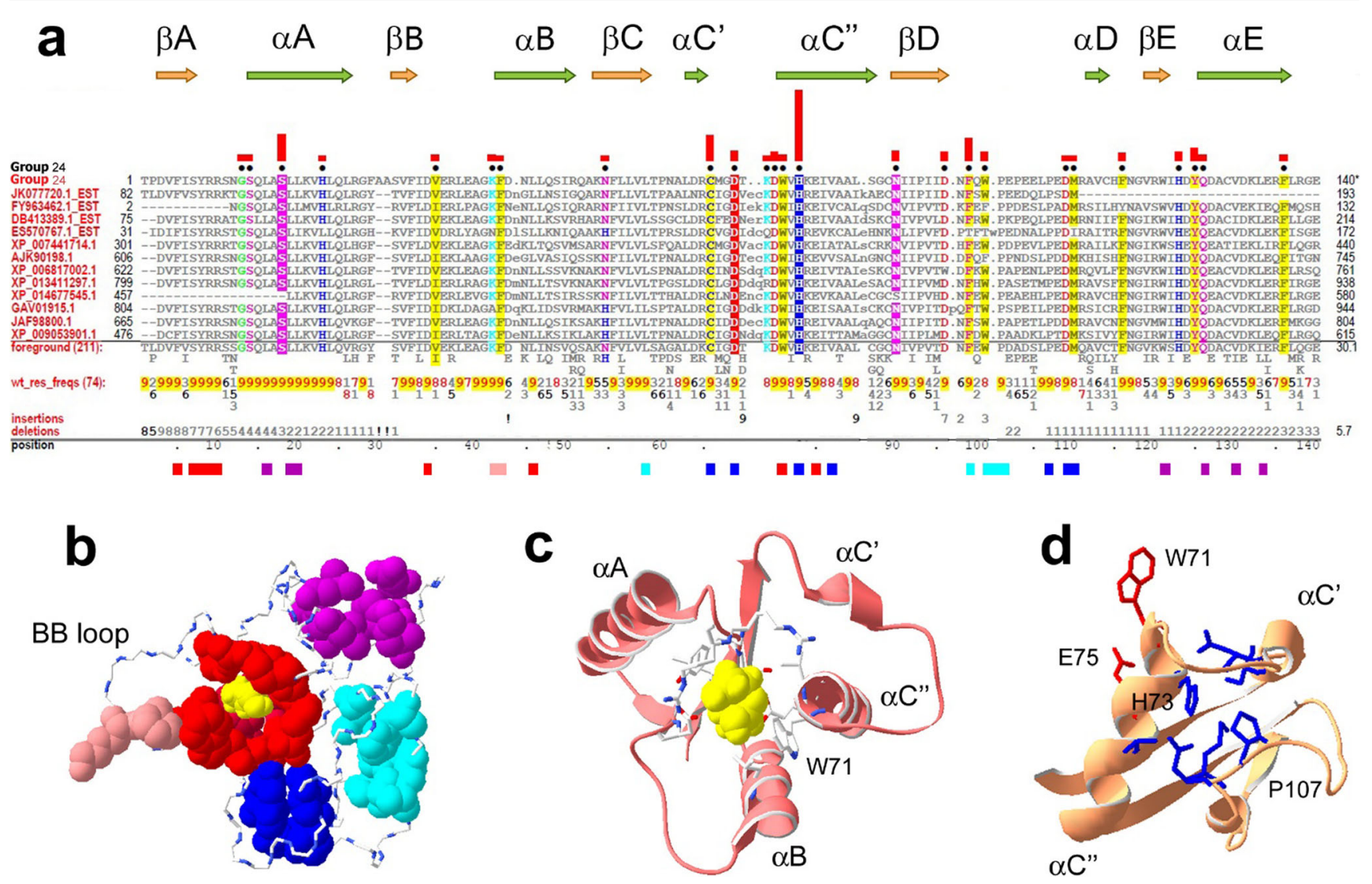

Fig. 7 Group 24 (SARM1-related) TIR domain sequence and structural features. a Group 24 contrast alignment. Colored horizontal bars indicate the mutually interacting residues shown in panel $\mathbf{b}$. b Clusters of group 24-specific residues. Color scheme: residues (also shown in panel c) contacting ribose, red; ribose, yellow; residues in the $\alpha \mathrm{C}$ and $\alpha \mathrm{D}$ regions, light and dark blue, respectively; residues mediating $\alpha \mathrm{A}-\alpha \mathrm{E}$ contacts, purple. c Ligand-binding pocket of SARM1 showing side chains for residues contacting ribose in human SARM1 bound to ribose (PDB ID: 6O0Q) (Horsefield et al. 2019). d H73 is on the opposite side of $\alpha \mathrm{C}^{\prime \prime}$ from W71 and E75, which bind ligand, and interacts with the other group 24 residues shown in blue; this cluster likely stabilizes this SARM1-specific structural motif consensus Box 2 motif (Carlsson et al. 2016). The first, second, and sixth residues of $-\mathrm{E}_{8}(\mathrm{R} / \mathrm{K})_{9} \mathrm{~L}_{9} \mathrm{E}_{7} \mathrm{~A}_{9} \mathrm{G}_{9}$ - are important for catalysis (Summers et al. 2016), and this region is associated with binding of SARM1 to TLR adapters MyD88 and TRIF (Carlsson et al. 2016).

Group 24-specific aA-aE contacts are aliphatic Group 24 TIRs lack the cluster of group 3 and 44 aromatic residues mediating helix-helix and helix-strand contacts for $\alpha \mathrm{A}$ and $\alpha \mathrm{E}$ (Figs. 5d and $6 \mathrm{c}$ ). Instead, the buried surface of $\alpha \mathrm{A}$ (positions 16, 19, 20 , and 24) mainly consists of leucines ( $>90 \%$ for each position) (Fig. 7a). The $\alpha \mathrm{A}-\alpha \mathrm{E}$ contacts are mostly through $\alpha \mathrm{A}$ leucine residues, but also involve W121 of $\beta \mathrm{E}$ (Fig. 7a, b).

\section{Conservation of group 24 residues forming the NAD-binding} pocket The residues that bind ribose in the ribose-SARM1TIR complex (PDB ID: 6O0Q) are shown in red in Fig. 7a, b. As for TIRs of catalytically active plant NB-LRR TIRs, the SARM1 ligand-binding pocket consists of $\alpha \mathrm{C}^{\prime \prime}, \alpha \mathrm{B}$, and $\beta \mathrm{A}$ residues and of the AA and BB loops (Fig. 7c). Each group 24 residue forming the ribose-binding part of the NAD-binding pocket is $>90 \%$ conserved, suggesting that NADase activity is a common function of these proteins.

Clusters of group 24 residues in the $\mathrm{aC}$ and $\mathrm{aD}$ regions The group 24 residues shown in light and dark blue in Fig. 7 a, b, and $\mathrm{d}$ are likely determinants of the SARM1-specific fold variant shown in Fig. 4d.

The group 24-specific EE loop residues The side chains of all residues that form the group 24-specific EE loop motif, $-\mathrm{H}_{9} \mathrm{D} /$ $\mathrm{E}_{9} \mathrm{Y}_{9} \mathrm{Q}_{9^{-}}$(Fig. 7a), correspond to a surface patch, possibly mediating intermolecular interactions.

\section{Group 10: TIRAP/Mal-related TIR domains}

Group 10 TIR domains occur in chordate proteins, in the adapter protein TIRAP/Mal, which is involved in TLR signaling (Fitzgerald et al. 2001; Horng et al. 2001). Based on X-ray crystallography (Lin et al. 2012; Snyder et al. 2013; Valkov et al. 2011; Woo et al. 2012), the TIRAP TIR domain has an abnormal fold, in that $\beta \mathrm{B}$ is shifted C-terminally by $\sim 15$ 
residues relative to other TIR domains, resulting in the absence of $\alpha \mathrm{B}$ and in an abnormally long, unstructured $\mathrm{AB}$ loop. NMR spectroscopy reveals, however, that in solution, the size and backbone conformation of the TIRAP TIR $\beta \mathrm{B}$ region is similar to that of groups 3 and 4 (Hughes et al. 2017). Highresolution cryo-EM of the tertiary structure of self-assembled, oligomeric complexes of TIRAP TIR domains in solution (Ve et al. 2017) revealed an open-ended, multifilamentous organization of TIR oligomers, with monomers of the assembly having a rather typical TIR structure, which resembles the NMR structure.

\section{Group 10 sequence patterns and features}

The consensus Box 1 of group 10 TIRs $\left(-\mathrm{Y}_{9} \mathrm{D}_{9} \mathrm{~V}_{9} \underline{\mathrm{C}_{7}} \mathrm{~V}_{6} \underline{\mathrm{C}_{9}} \mathrm{H}_{9^{-}}\right)$ differs from the global consensus by two cysteines (Fig. 8a), and Box 2, the BB loop, is highly conserved. However, group 10 lacks both Box 3 and the aromatic residues of $\alpha \mathrm{A}$ and $\beta \mathrm{E}$, with which the conserved aromatic residues of Box 3 interact in groups 3 and 4 (Figs. 5d and 6c).
AA loop charged residues As for group 2 (plant NB-LRR receptor; Fig. 3a, c) and group 24 (SARM1-related; Fig. 7a) TIRs, group 10 TIRs conserve AA loop charged residues (Fig. $8 \mathrm{a}, \mathrm{b})$.

Conserved $\beta$-sheet cysteines Group 10 TIRs conserve $\beta$ A cysteines ( $\mathrm{C} 5$ and $\mathrm{C} 7 \mathrm{in}$ Fig. 8a), the side chains of which are on the convex side of $\beta$-sheet facing $\alpha \mathrm{B}, \alpha \mathrm{C}$, and $\alpha \mathrm{D}$. In available structures of human TIRAP, C5 forms a disulfide bond with C48 (Lin et al. 2012; Snyder et al. 2013; Valkov et al. 2011; Woo et al. 2012) that, however, appears to be a crystallographic artifact, which accounts for TIRAP's significant structural deviation from other TIRs. The NMR structure of human TIRAP and the cryo-EM structures of oligomeric TIRAP complexes (Hughes et al. 2017; Ve et al. 2017) lack the C5-C48 disulfide bond, and, unlike the BB loop Box 2 motif $\left(-\mathrm{R}_{9} \mathrm{D}_{9}-\phi-\phi-\mathrm{P}_{8} \mathrm{G}_{9}-\right)$, C48 is only $\sim 50 \%$ conserved in TIRAP-related proteins (Fig. $8 \mathrm{a})$. C7, which was proposed to be involved in the redox regulation of TIRAP through glutathionylation (Hughes et al. 2017), occurs in $>90 \%$ of group 10 TIRs and in $<10 \%$ of other TIRs (Figs. 2a and 8a). C31 in $\beta \mathrm{B}$ is another group 10-specific

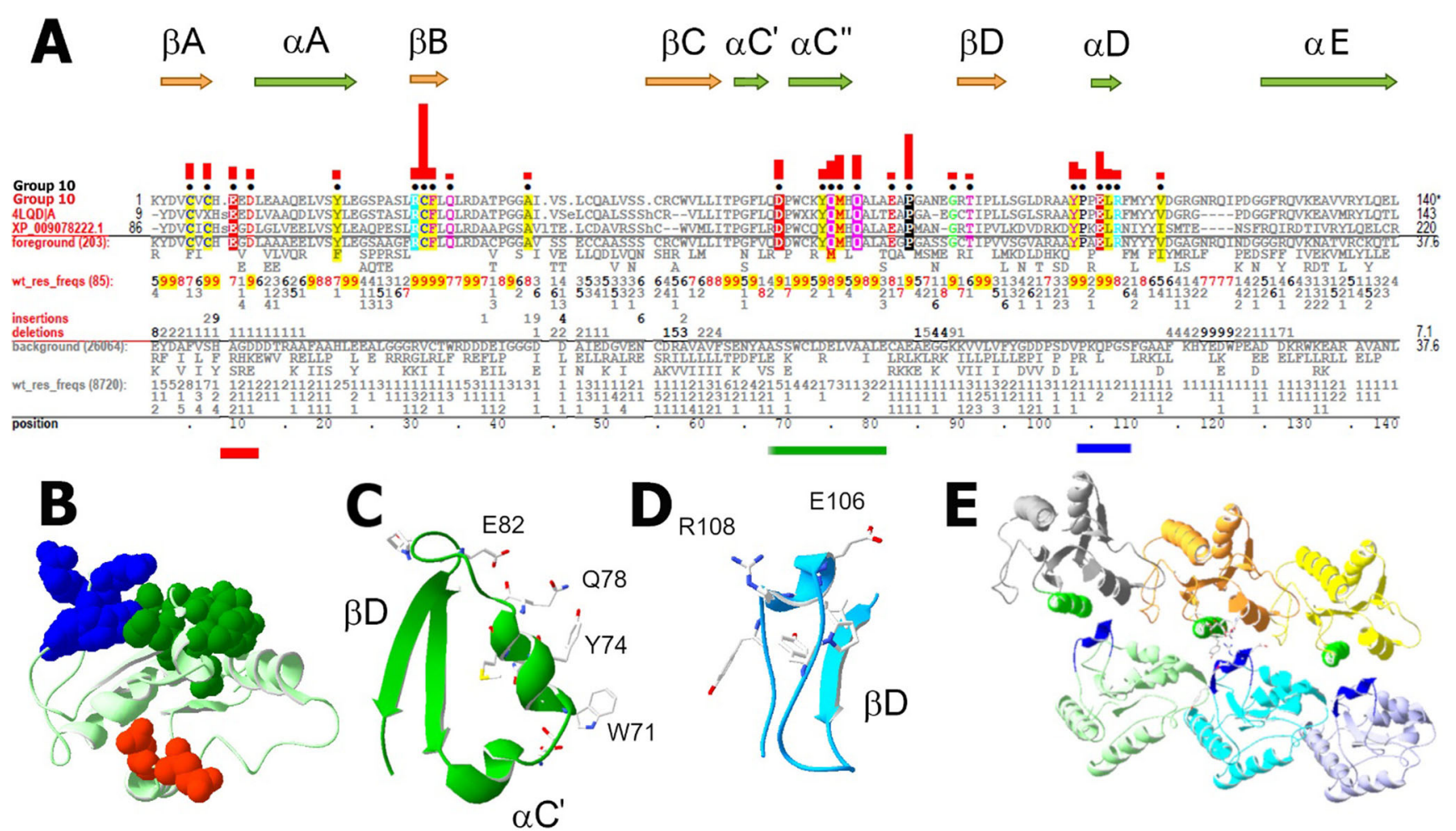

Fig. 8 Group 10 (TIRAP-related) TIR domains. a Group 10 contrast alignment. Horizontal bars beneath indicate residues shown in panel $\mathbf{b}$ using the same color scheme. b Clusters of surface-exposed group 10 residues in chain A of the oligomeric TIRAP assembly (PDB ID: 5UZB) (Ve et al. 2017). Color scheme: AA loop residues, red; $\alpha \mathrm{C}$ region, dark green; $\alpha \mathrm{D}$ region, blue. $\mathbf{c}$ Residues in the $\alpha \mathrm{C}$ region. W71, Y74, Q78, and E82 are juxtaposed on the surface to form a large patch. $\mathbf{d}$ Residues in the $\alpha \mathrm{D}$ region. E106-L107-R108 are characteristic of
TIRAP-related TIR domains. e $\alpha \mathrm{C}$ and $\alpha \mathrm{D}$ conserved surface patches mutually interact in oligomeric TIRAP TIR protofilaments. The image represents the double-stranded fragment of TIRAP signalosome composed of six TIRAP monomers (PDB ID: 5UZB) (Ve et al. 2017). $\alpha \mathrm{C}^{\prime}$ helices are shown in green for 3 TIRs forming the "upper" strand of the double-stranded protofilament. $\alpha$ Ds are shown in dark blue for 3 TIRs forming the lower strand. For clarity, reciprocal interactions of upper TIR $\alpha$ Ds with lower TIR $\alpha$ Cs are not shown 
cysteine on the same side of the $\beta$-sheet and contacts several residues of $\alpha \mathrm{A}$ and the $\mathrm{BB}$ loop; it is neither surface-exposed in resolved structures nor involved in intermolecular contacts in the oligomeric TIRAP complex (Ve et al. 2017). An additional disulfide bond connecting $C 55$ of $\beta C$ to $C 90$ of $\beta D$ occurs in human TIRAP (Snyder et al. 2014; Valkov et al. 2011) but not in other group $10 \mathrm{TIRs},<10 \%$ of which conserve C90 (Fig. 8a).

Conformational flexibility of $\beta B$ and adjacent loops The significant difference between crystal and solution structures of group 10 TIRs indicates that the $\beta \mathrm{B}$ region is conformationally flexible. This flexibility might be important for function because protein interfaces formed by disordered regions typically have a better fit and bind a larger set of targets (Wright and Dyson 2015). Indeed, this region mediates homomeric interactions in TIRAP filaments and also heteromeric interactions with MyD88 and certain TLR TIRs (Javmen et al. 2018; Ve et al. 2017). The high flexibility of group $10 \mathrm{BB}$ loops might be due to a high number of residues with a small side chain, as the most frequent BB loop motif (-R $\left.\mathrm{R}_{9} \mathrm{D}_{9} \underline{\mathrm{A}}_{7} \mathrm{~T}_{3} \mathrm{P}_{8} \underline{\mathrm{G}}_{9} \underline{\mathrm{G}}_{6} \underline{\mathrm{A}}_{8^{-}}\right)$has two glycines and two alanines (Fig. 8a).

Two group 10 residue clusters forming surface patches Surface patches are formed by clusters associated with the $\alpha \mathrm{C}$ - and $\alpha \mathrm{D}$-regions (Fig. 8a-d). The N-terminal cluster (green bar in Fig. 8a) includes nine group 10 residues in the 23-residue long region between $\beta C$ and $\beta D$ (Fig. 8a-c).

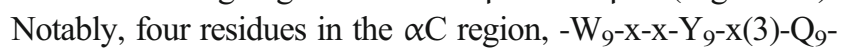
$\mathrm{x}(3)-\mathrm{E}_{8^{-}}$, are juxtaposed on the TIR surface (Fig. 8c). The Cterminal cluster (the dark blue bar in Fig. 8a) is a more compact, 6-residue motif (- $\left.\mathrm{Y}_{9} \mathrm{P}_{9}-\mathrm{X}-\mathrm{E}_{9} \mathrm{~L}_{9} \mathrm{R}_{8}-\mathrm{X}-\mathrm{X}-\mathrm{Y}_{8^{-}}\right)$centered on the short $3_{10}$-helix D (Fig. 8a, b, d). Cell-permeating decoy peptides based on these segments inhibited TLR signaling (Couture et al. 2012). These two conserved surface patches, located in $\alpha \mathrm{C}$ and $3_{10}$-D helix of TIRAP TIRs, correspond to TIR interfaces that mediate self-assembly of filamentous TIRAP complexes in solution (Ve et al. 2017 and Fig. 8e). Other TIR-derived decoy peptide studies suggest that nearly the same interfaces mediate the heterotypic TIRAP interactions with both MyD88 and TLR TIRs (Javmen et al. 2018; Toshchakov and Javmen 2020; Ve et al. 2017). Notably, the group 10 surface patches are larger (especially the $\alpha \mathrm{C}$ site) than the actual TIR-TIR contact areas in TIRAP protofilaments (Fig. 8c-e), which provides an explanation for the multispecificity of TIR-TIR interactions mediated by these regions: different segments of $\alpha \mathrm{C}^{\prime \prime}$ may be critical for interactions with TIRs in different TIRAP heterocomplexes (for detailed discussion, see references Javmen et al. 2018, Toshchakov and Javmen 2020, and Ve et al. 2017).

\section{Groups 23 and 32: MyD88-like proteins}

MyD88 is an adapter protein utilized by two large metazoan receptor families, i.e., the IL-1R family and TLRs (Medzhitov et al. 1998; Wesche et al. 1997), which harbor group 4 and 3 TIRs, respectively. MyD88-related TIRs belong to two groups: group 23 TIRs from non-arthropod metazoans and group 32 TIRs from arthropods (Fig. 1e). Group 23 is formed mostly by chordate proteins, but also includes representative cnidarian TIRs, several TIRs of lower deuterostomes (both echinoderms and hemichordates), and TIRs of two protostome phyla, i.e., Annelida and Brachiopoda. These organisms typically have one gene encoding a protein with a group 23 TIR; however, some species of protostomes and deuterostomes, including echinoderms, may have multiple genes encoding MyD88-like proteins (Ren et al. 2014; Tassia et al. 2017). A typical MyD88-like protein has two protein interaction domains, an N-terminal death domain, and a C-terminal TIR (Hardiman et al. 1996). Invertebrates may have more complex domain architectures (Lee et al. 2011; Supplemental Fig. 2). For example, Arthropoda MyD88s typically have a phosphoinositide-binding domain, C-terminally to the TIR (Horng and Medzhitov 2001; Marek and Kagan 2012). All 3 "Boxes" of conserved residues are present in MyD88-like TIRs. The typical Box 1 sequence of group 23 is $\mathrm{F}_{8} \mathrm{D}_{9} \mathrm{~A}_{9} \mathrm{~F}_{9} \mathrm{I}_{7} \underline{C}_{9} \mathrm{Y}_{9^{-}}$(Fig. 9a). Box 2 is highly conserved, with a consensus $\left(-\mathrm{R}_{9} \mathrm{D}_{9} \mathrm{~V}_{7} \mathrm{~L}_{9} \mathrm{P}_{9} \mathrm{G}_{9}\right.$ ) similar to that of TLRs (group 3), IL-1R family (group 4), and TIRAPs (group 10). E23 at the $\mathrm{C}$-terminal end of $\alpha \mathrm{A}$ is conserved in all four groups, along with the Box 2 -RD- motif (Figs. 5c, 6d, 8a, and 9a). Box 3 (residues 129 and 130 ) has the typical $-\mathrm{F}_{8} \mathrm{~W}_{9^{-}}$pattern, which is similar to that of groups 3 and 4 , but dissimilar to that of TIRAP (group 10).

\section{Group 23 residue patterns and structural features}

Conserved motifs in the $\mathrm{aC}$ and $\mathrm{aD}$ regions mark sites mediating TLR signalosome assembly Two motifs in the $\alpha \mathrm{C}$ and $\alpha \mathrm{D}$ regions and a third in $\beta \mathrm{E}$ distinguish the MyD88-like TIRs of non-arthropods from other TIRs (Fig. 9a, c). These motifs, together with a group 23 conserved $\beta \mathrm{B}$ region (which is similar to the homologous region in groups 3, 4, and 10), correspond to TIR sites mediating the assembly of TLR signaling complexes (Javmen et al. 2018; Toshchakov and Javmen 2020; Ve et al. 2017). The $\alpha \mathrm{C}$ and $\alpha \mathrm{D}$ clusters correspond to homologous regions conserved in TIRAP TIRs (group 10), though the group 23 variant of the $\alpha \mathrm{C}^{\prime \prime}$ surfaceforming motif $\left(-73 \mathrm{D}_{9} \mathrm{~F}_{9^{-}} \mathrm{X}-\mathrm{X}-\mathrm{K}_{9^{-}} \mathrm{x}(3)-\mathrm{S}_{8^{-}}\right)$differs from the

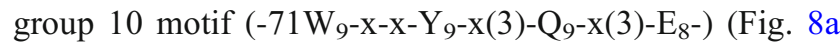
versus Fig. 9a) - though both form the exposed surface of $\alpha \mathrm{C}^{\prime \prime}$ (Figs. 9d and 8c). For both groups 23 and 10, residues conserved in the region between $\beta \mathrm{D}$ and $\beta \mathrm{E}$ (i.e., $-\mathrm{F}_{7} \mathrm{P}_{9^{-}}-\mathrm{S}_{7^{-}}$ $\mathrm{I}_{9} \underline{\mathrm{L}_{9} \mathrm{R}_{8}}-\mathrm{X}-\mathrm{X}-\mathrm{T}_{9^{-}}$and $-\mathrm{Y}_{9} \underline{\mathrm{P}_{9}}-\mathrm{X}-\mathrm{E}_{9} \underline{\mathrm{L}_{9} \mathrm{R}_{8}}-\mathrm{X}-\mathrm{X}-\mathrm{Y}_{8^{-}}$, respectively) are mostly in the segment oriented orthogonally to the $\beta$-sheet (Figs. 9e and 8d). These regions in both adapters play a critical role in signaling, as these can interact in homo- and heterotypic fashion with the $\alpha \mathrm{C}$ motif of certain TIRs, leading to signal- 

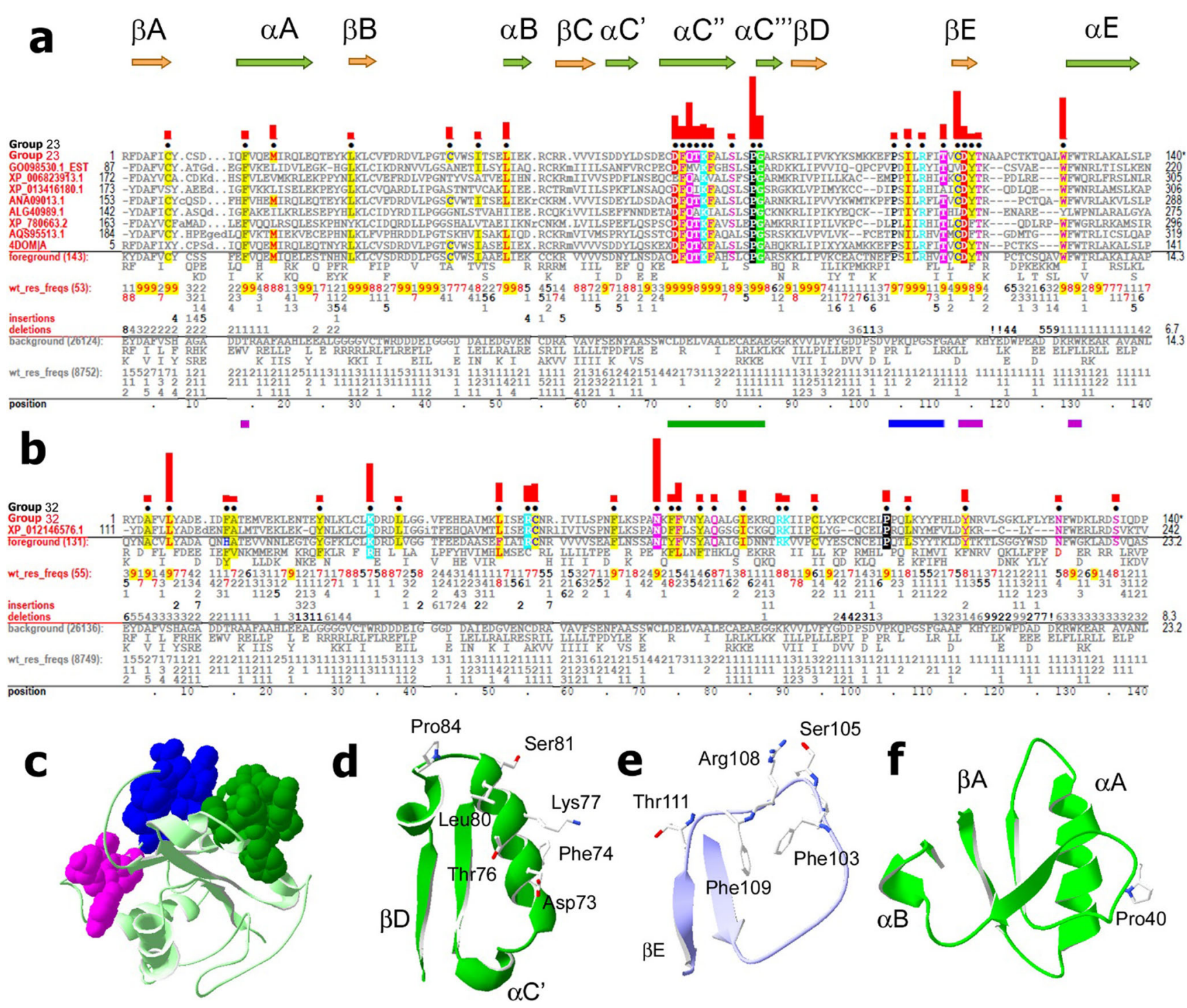

Fig. 9 Group 23 and 32 (MyD88-like) TIR domains. a Group 23 TIR domain contrast alignment. Horizontal bars indicate three groups of residues shown in the same colors as in panel c. b Group 32 contrast alignment. c Solution NMR structure of human MyD88 (PDB ID: 2JS7), a representative group 23 TIR. Group 23-

dependent adapter oligomerization and initiation of intracellular signaling (Fig. 8e; Javmen et al. 2018; Toshchakov and Javmen 2020; Ve et al. 2017).

The MyD88-like-specific sequence of $\beta E$ MyD88-like proteins conserve a $\beta \mathrm{E}$ motif $\left(-\mathrm{C}_{9} \mathrm{D}_{9} \mathrm{Y}_{8} \mathrm{~T}_{9^{-}}\right)$that differs from that of other TIRs (Fig. 9a). Motif residues are largely surface exposed and may be involved in signaling interactions. C113 and $\mathrm{Y} 115$ of the $\beta \mathrm{E}$ motif also interact intramolecularly with Box 3 aromatic residues (not shown).

Conserved contacts between $\mathrm{aA}$ and $\mathrm{aE} \alpha \mathrm{A}$ residues $\mathrm{F} 14$ and M18, which are juxtaposed in 3D, are $>90 \%$ and $>80 \%$ conserved in MyD88-like TIR domains, respectively (Fig. 9a),

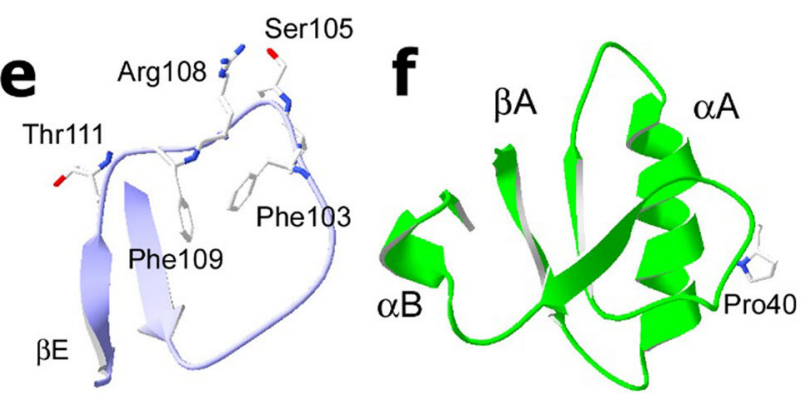

specific residues in $\beta \mathrm{E}$ are shown in magenta; residues in the $\alpha \mathrm{C}$ and $\alpha \mathrm{D}$ regions are shown in green and blue, respectively. $\mathbf{d}$ Group 32 residues in the $\alpha \mathrm{C}$ region form the exposed surface of $\alpha \mathrm{C}^{\prime \prime}$. e Segment between the $\beta D$ and $\beta E$ strands. f Atypical BB loop structure of the human MyD88 TIR domain

and their side chains interact with the Box 3 residues $\mathrm{W} 130$ and F129, respectively, through aromatic and sulfur-aromatic interactions. This forms a network of interactions, analogous to those shown in Figs. $5 \mathrm{~d}$ and $6 \mathrm{c}$ for group 3 and 4 TIRs, that presumably stabilize core structural elements on the concave side of the $\beta$-sheet.

Unusual structure of BB loop The known structure of the MyD88 BB loop differs from that of other TIRs having the conserved Box 2 motif, i.e., TIRs of TLRs, IL-1Rs, and TIRAPs, inasmuch as residues on the $\mathrm{N}$-terminal side of $\alpha \mathrm{B}$ are in an extended conformation (though residues of $\beta B$ and those near the $\alpha \mathrm{B}$ C-terminal end are more typical) (Fig. 9f), despite all residues of the Box 2 motif -RD- $\phi-\phi$-PG- are 
highly conserved in all four groups, as is the E23 in the Cterminal turn of $\alpha \mathrm{A}$ (Fig. 9a). Unlike the TIRAP TIR, which has drastically different BB loop conformations in solution and crystal, the NMR and X-ray structures of the MyD88 BB loop are nearly identical (Ohnishi et al. 2009; Snyder et al. 2013). This apparent discord between conservation of motifs yet dissimilar folds suggests that the BB loop requires conformational flexibility, which manifests in different BB loop conformations in monomeric adapter TIRs, including the differences in solution and crystal structures of the TIRAP BB loop.

\section{Group 37: TRIF-like TIRs}

Group 37 consists of TIR domains related to those of TRIF, also known as TICAM-1, a TLR adapter protein that participates in TLR3 and TLR4 signaling, leading to a robust activation of type I interferons (Oshiumi et al. 2003; Yamamoto et al. 2002). TRIF-like proteins occur in vertebrates (Tassia et al. 2017). Group 37 consists exclusively of chordate TIRs (Supplemental Fig. 3), which include TIRs of elephant shark, many bony fishes, and tetrapods, but not TIRs of lancelet, lamprey, or Ciona (Supplemental Fig. 3) - suggesting that they are restricted to gnathostomes.

\section{Group 37 residue patterns and structural features}

BB loop and $a B$ motifs Many TRIF-like TIR residues are within $\beta A, \beta B$, and $\beta D$ (Fig. 10a) and appear to play a predominantly structural role not directly related to signaling. Among the group 37 surface-exposed residues are those of the BB loop and $\alpha \mathrm{B}$ (Fig. 10a-c). The BB loop motif differs in its N-terminal half $\left(-35 \mathrm{E}_{8} \mathrm{D}_{9} \mathrm{~F}_{9} \mathrm{xxP}_{6} \mathrm{G}_{9^{-}}\right)$, from the Box 2 motif (-xRDxxPG-) typical of groups 3, 4, 10, 23, and 32. Cell-permeable peptides derived from both conserved regions, but not from other surface-exposed segments of TRIF TIR, potently inhibited the TLR4-mediated signaling (Piao et al. 2013).

$\mathrm{aE}$ contacts In group $37, \alpha \mathrm{E}$ contacts the $\beta$-sheet and $\alpha \mathrm{A}$ through conserved F129 and V133, which interact with conserved L121 and F95 of the $\beta$-sheet but not with conserved $\alpha \mathrm{A}$ residues (Fig. 10a, e).

\section{Prokaryotic TIR domains}

BPPS partitioned bacterial TIRs into 23 groups, only one of which, group 17 , contained a $\sim 20 \%$ admixture of eukaryotic genes, all of which are from protozoans and lower metazoans (Fig. 1b, c). Unlike most metazoan groups, each bacterial group typically contains proteins with different domain architectures. Here, we review, as an example, the features of two of the largest bacterial groups (groups 14 and 6) and of the only bacterial TIR group with a known structure (group 35).

\section{Group 14}

Group 14 is the largest prokaryotic group ( 825 sequences) that consists of $\sim 50 \%$ Proteobacteria, $\sim 25 \%$ Actinobacteria, $\sim 5 \%$ Cyanobacteria, and $\sim 5 \%$ Firmicutes proteins (Fig. 1g). Box 1 of group 14 TIRs has a consensus of $-\mathrm{P}_{2} \mathrm{D}_{4} \mathrm{~V}_{5} \mathrm{~F}_{9} \mathrm{I}_{4} \mathrm{~S}_{9} \mathrm{Y}_{5^{-}}$, which corresponds to the consensus of all TIR domains except for the $\mathrm{N}$-terminal residue. Boxes 2 and 3 do not correspond to typical TIR domains. Most group 14-specific residues are located in the N-terminal region of the TIR and include D12 of the AA loop, a pattern of non-polar residues in $\alpha \mathrm{A}$, and a motif that spans $\beta \mathrm{B}$ and adjacent loops (Fig. 11). Additional conserved residues are located in the third and fourth helical regions (positions 70-73 and 102-106) and near $\beta E$ (Fig. 11). Because proteins of this group are not well studied and lack structural information, it is difficult to interpret the functional significance of pattern residues.

\section{Group 6}

Group 6 bacterial TIR domains mainly occur in actinobacterial proteins (Fig. 1g). Proteins of this class can have different domain architectures, but often combine an $\mathrm{N}$-terminal TIR with multiple C-terminal tetratricopeptide repeats and are large (>700 aa).

Residue patterns of Group 6 TIRs Boxes 1, 2, and 3 are not conserved in group 6. Instead, the group 6-specific consensus patterns for $\beta \mathrm{A}$ (Box 1) and the BB loop (Box 2) are $\mathrm{R}_{3} \mathbf{D}_{7} \mathrm{~F}_{3} \mathrm{~F}_{5} \mathrm{~V}_{4} \mathrm{~S}_{8} \mathbf{Y}_{7^{-}}$and $-\mathrm{W}_{4} \mathbf{D}_{5} \mathrm{~A}_{1} \mathrm{~V}_{1} \mathbf{P}_{\mathbf{3}} \mathbf{G}_{\mathbf{6}^{-}}$, respectively, and the two conserved aromatic residues of Box 3, i.e., F129 and W130, are replaced by two conserved aliphatic residues (Fig. 12). The two most characteristic residues of group 6 are W15 and W18 (Fig. 12), which likely form the hydrophobic side of $\alpha \mathrm{A}$ and thus part of the structural core.

\section{Group 35}

Group 35 is phylogenetically similar to group 14, with the most from Proteobacteria, followed by Actinobacteria, Firmicutes, Bacteroides, and Cyanobacteria (Fig. 1g). These proteins are relatively small $(<300 \mathrm{aa})$ and typically have a Cterminal TIR along with an N-terminal domain of different types. Three structures for two representative proteins are available.

Group 35 residue patterns and structural features Most Group 35 conserved residues are in the N-terminal half of the TIRs (Fig. 13a). Many of these form a surface-exposed 


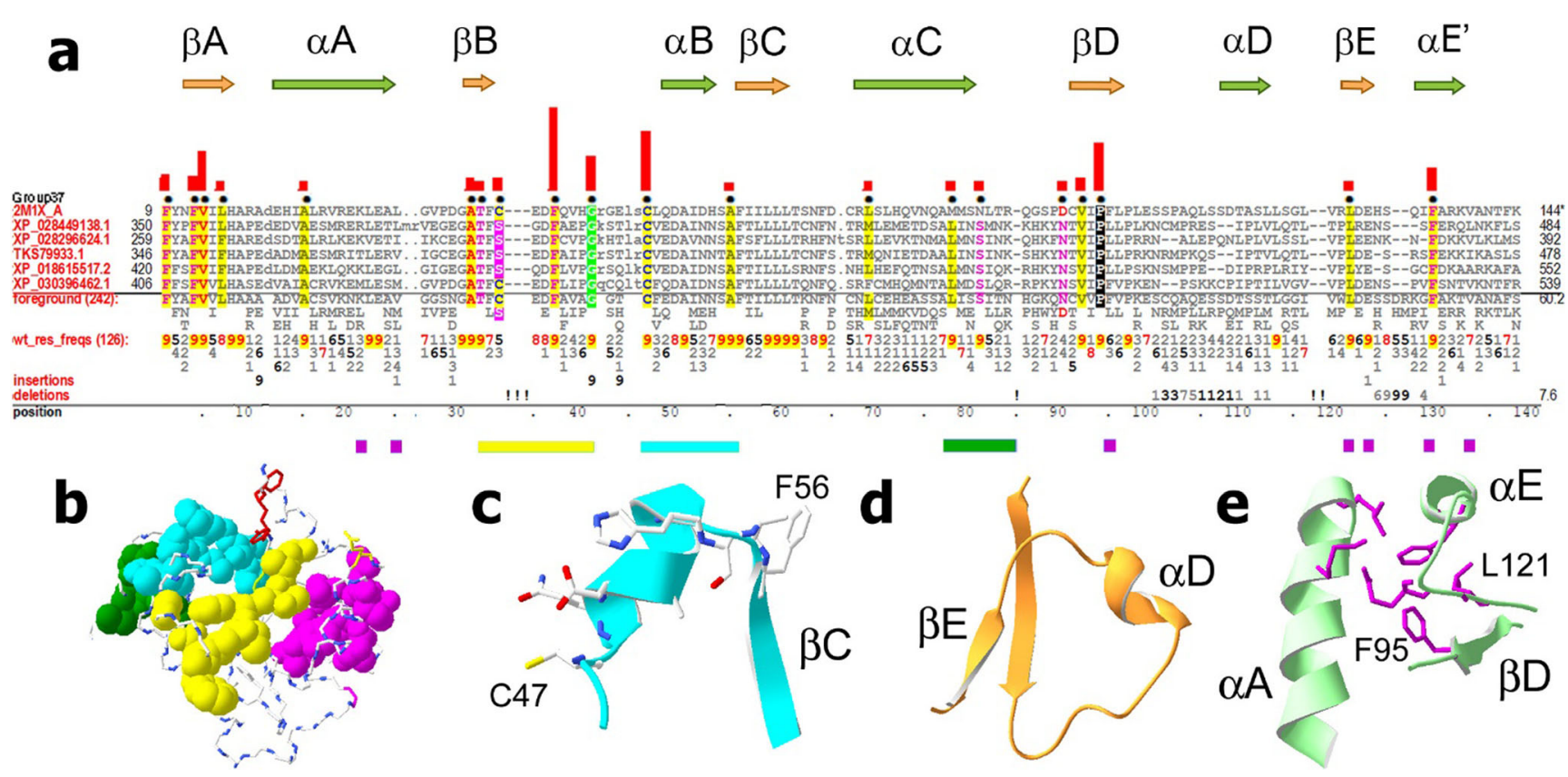

Fig. 10 TRIF-like TIR domains. a Group 37 TIR domain contrast alignment. Horizontal bars beneath the alignment indicate groups of residues shown in the same colors as in panel b. b Group 37 conserved residue clusters. The NMR structure of human TRIF

patch (Fig. 13b). In addition to the N-terminal residues, there are 5 conserved residues in the C-terminal half (Fig. 13a).

Box 2 of group 35 TIRs differs from the typical regional sequence described above for groups 3 and 4 . There are two motifs in the BB loop region of group 35 TIRs: $-\mathrm{V}_{8} \mathrm{~W}_{9} \mathrm{Y}_{6} \mathrm{D}_{9^{-}}$, which forms a 4-residue "bulge," immediately after $\beta \mathrm{B}^{\prime}$ (Chan et al. 2009) (Fig. 13a, c); and $-\mathrm{G}_{9} \mathrm{D}_{8} \mathrm{~S}_{9} \mathrm{~L}_{8^{-}}$in the Cterminal half of BB loop (Fig. 13a, c). Two conserved glycines, i.e., $\mathrm{G} 30$ and $\mathrm{G} 43$, are located at the tips of the $\mathrm{AB}$ and BB loops, respectively (Fig. 13c).

The group $35 \mathrm{C}$-terminal conserved segment corresponds to $\beta \mathrm{D}$ (Fig. 13a, d), the residue side chains of which are buried with the aromatic ring of W95 pointing towards $\alpha \mathrm{D}^{\prime}$ and $\alpha \mathrm{D}^{\prime \prime}$
(PDB ID: 2M1X) (Enokizono et al. 2013) was used to generate images for panels b-e. c Conserved $\alpha \mathrm{B}$ residues. d TRIF-specific conformation of the $\alpha \mathrm{D}$ region. $\mathrm{e}$ Residues mediating interaction of $\beta \mathrm{D}$ and $\beta \mathrm{E}$ with $\alpha \mathrm{A}$ and $\alpha \mathrm{E}^{\prime}$

(Fig. 13d). The $\alpha \mathrm{D}$ region in group 35 has a unique fold (Fig. $4 \mathrm{c}$ ), which is formed by two antiparallel helices oriented orthogonal to the $\beta$-sheet (Figs. $4 \mathrm{c}$ and 13d).

\section{Discussion}

TIR domain-containing proteins occur among all major forms of cellular life. The primary and nearly universal function of TIR domains appears to be the mediation of regulated protein interactions in signaling. Prokaryotes use TIR domains as a signaling unit in a variety of functionally diverse signaling cascades (Spear et al. 2009). The multicellular organisms,

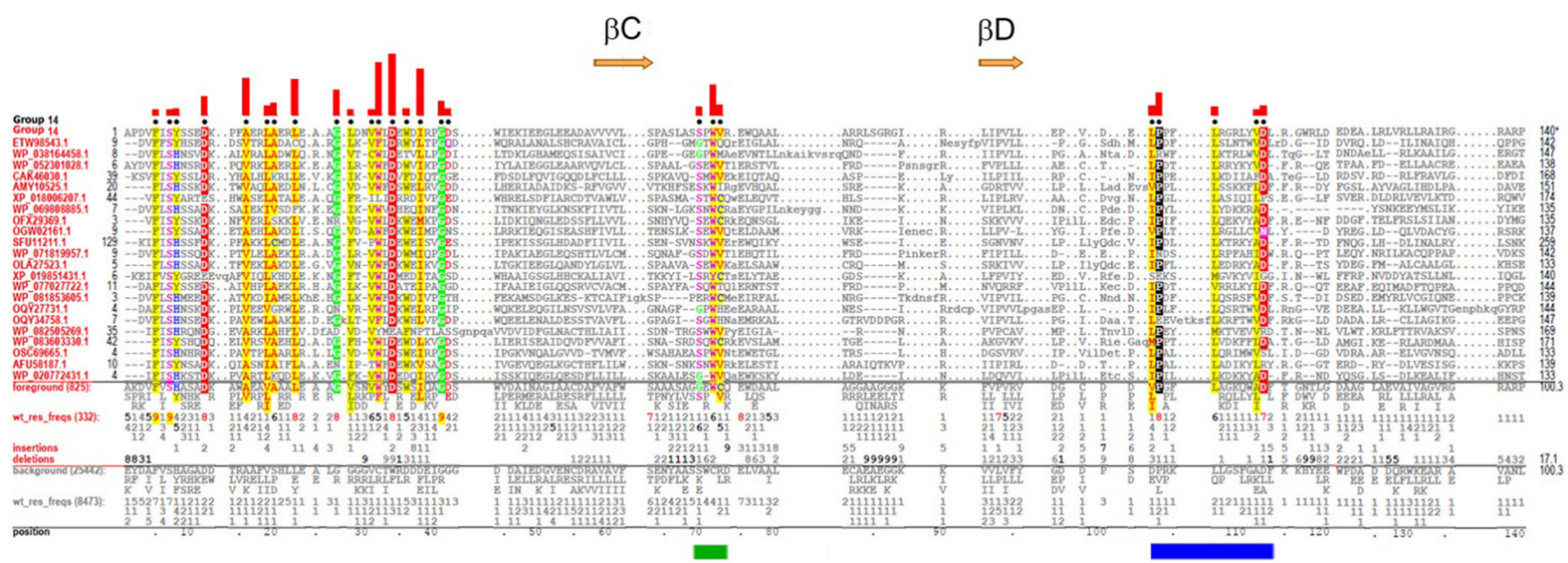

Fig. 11 Group 14 TIR domain contrast alignment. Green and blue bars beneath the alignment indicate pattern residues of third and fourth helical regions 


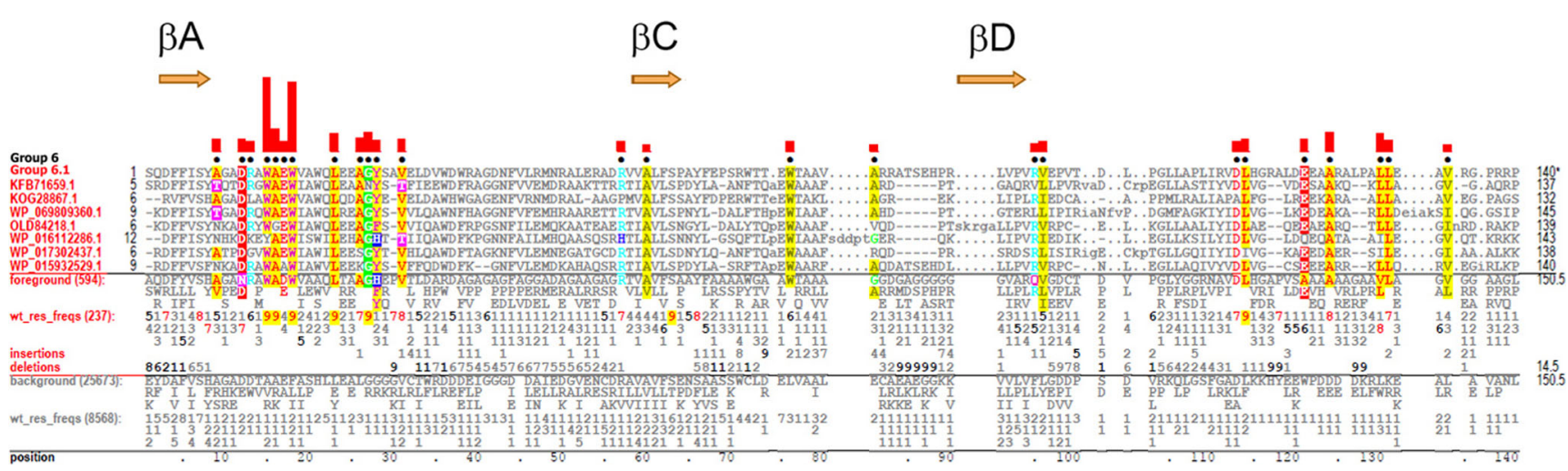

Fig. 12 Group 6 TIR domain contrast alignment

however, use this type of protein domain in a more specialized fashion, primarily as a unit mediating the assembly of intracellular signaling complexes to signal microbial presence, and initiate and regulate antimicrobial defense mechanisms. A later acquired function of TIR domains, unique to arthropods and mediated by Toll orthologs, is in early embryogenesis, in addition to participating in defense. The functional similarity of TIR domains in plant and animal immune defense is apparently coincidental and likely stems from a strong evolutionary pressure to develop non-self-sensing and antimicrobial defense mechanisms concomitantly with development of multicellularity - together with the efficacy of TIRs as a general signaling unit, as indicated by their universal evolutionary distribution in this role.

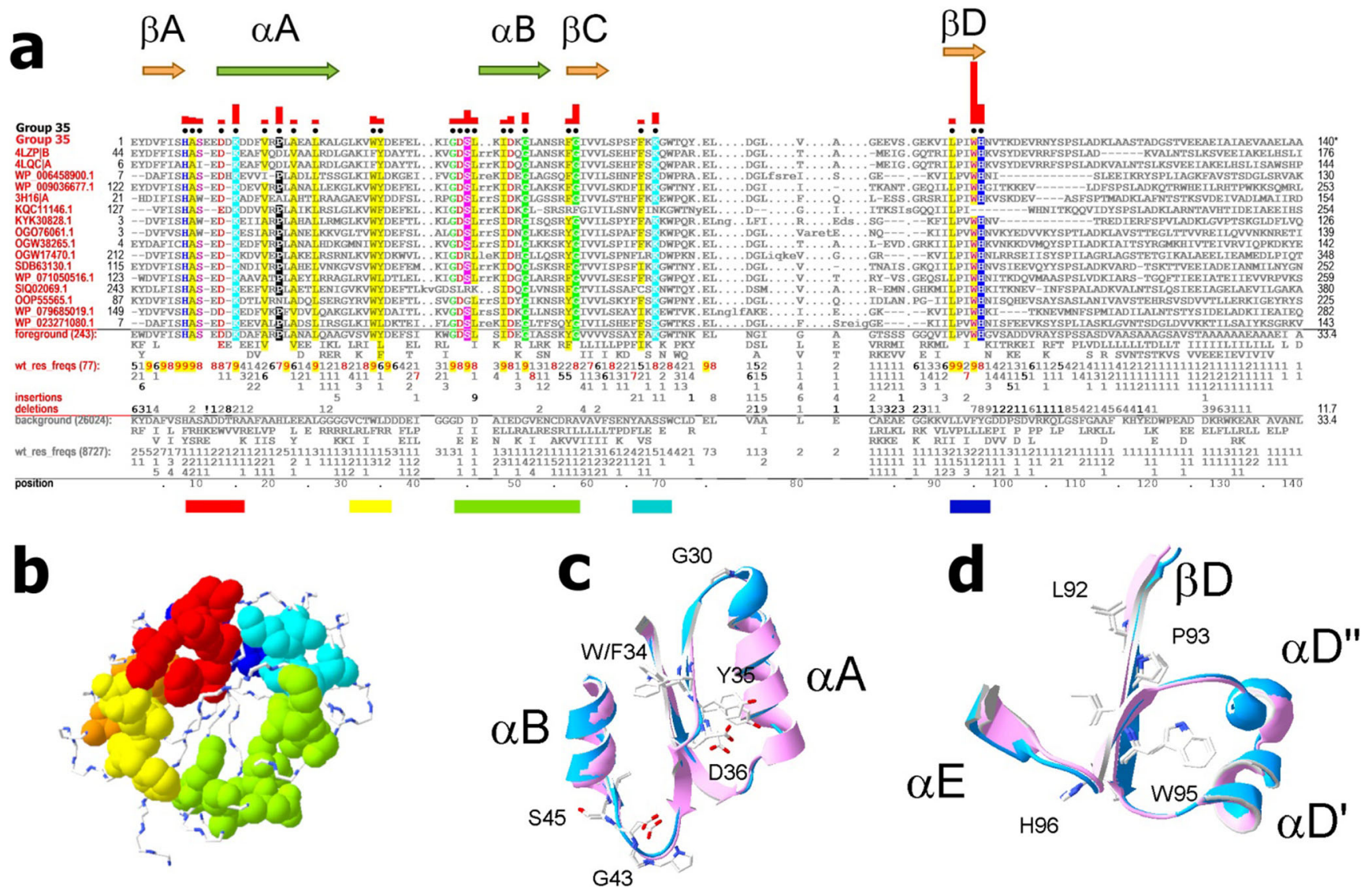

Fig. 13 Group 35 bacterial TIR domains. a Group 35 contrast alignment. Horizontal bars indicate clusters of conserved residues, shown in the same colors as in panel b. b Group 35 conserved residue clusters for the TIR domain of Paracoccus denitrificans PdTIR protein (PDB ID: 3h16) (Chan et al. 2009). Colors correspond to the color of horizontal bars below the alignment in panel a. $\mathbf{c}$ Conserved residues in the segment between $\alpha \mathrm{A}$ and $\alpha \mathrm{B}$. Shown are superimposed regions of TIR domains from Paracoccus denitrificans PdTIR protein (PDB ID: 3h16) (Chan et al. 2009) and Brucella protein TcpB (PDB ID: 4lqc) (Snyder et al. 2014). d Conserved $\beta D$ residues. Shown are superimposed regions of TIR domains as in panel $\mathbf{c}$ 
The universal evolutionary distribution of TIR domains suggests this protein fold emerged early in the development of cellular life. Therefore, it is not surprising that some groups of TIR domains have acquired additional functions. One such function, found in SARM1 and some plant and bacterial TIRs, is the ability to catalyze NAD degradation (Essuman et al. 2018; Horsefield et al. 2019; Wan et al. 2019). Another function, found in some pathogenic bacteria, is the secretion of cell-permeable TIR proteins to subvert the antibacterial defense mechanisms mediated by host TIRs (Alaidarous et al. 2014; Cirl et al. 2008). Yet another, more recently evolved function is their participation in cytokine signaling, the emergence of which (and of cytokine signaling in general) coincides with the development of the adaptive immunity in jawed vertebrates (Flajnik and Kasahara 2010; Liongue et al. 2016; Rivers-Auty et al. 2018), and reflects the increased complexity of associated regulatory mechanisms.

The emergence of groups 4 and 37 of our hierarchy can be directly associated with the emergence of cytokine signaling in gnathostomes. Group 4 TIRs mediate downstream signaling for the IL-1R family, whereas group 37 mediates upstream signaling that induces type I interferons, cytokines important for antiviral defense. Notably, our statistical analysis has identified IL-1R and TRIF groups but failed to identify a group of TRAM-related TIRs. TRAM is an auxiliary TLR adapter that function in conjunction with TRIF to mediate the TLR4dependent TRIF signaling (Oshiumi et al. 2003). The failure to identify a TRAM group is likely due to this group's small size. Thus, Sullivan et al. found that TRAM evolved simultaneously with TRIF in early chordates as a product of the second whole genome duplication (Sullivan et al. 2007). The TRAM gene, however, was lost in the early evolution of rayfin fish (Sullivan et al. 2007).

The long evolutionary history of TIR domains explains their abundance and diversity, but complicates the analysis of TIR functions. Particularly, the molecular mechanisms that underlie selectivity of TIR domain interactions are not well articulated at this time. The literature typically cites the absence of specific binding motifs, which are common for the entire group, yet recognizes that the TIR domains interact specifically with certain members of the family, while also often demonstrating "multispecificity," being able to interact with a subgroup of TIRs (Gay et al. 2014; Jiang et al. 2006; Toshchakov et al. 2011; Ve et al. 2017). There are two mechanistic explanations for the multispecificity of TIR-TIR interactions. The first is that individual TIRs often can simultaneously interact with several other TIRs through nonoverlapping interaction sites. The second is that the individual sites can also be "multispecific" and may interact with different TIRs with a similar affinity (Javmen et al. 2018; Ve et al. 2017). Recent studies have advanced our understanding of the topology of TIR domain interactions for certain TLRs and TLR adapters (Javmen et al. 2018; Nanson et al. 2019;
Toshchakov and Javmen 2020; Ve et al. 2017). This new knowledge has led to plausible models for the architecture of TLR signaling complexes (Javmen et al. 2018; Ve et al. 2017). The known examples of TIR-TIR interaction modes in signaling complexes however cover a miniscule portion of the TIR domains existing in nature; and, even for these few examples, the molecular features responsible for the functional specificity of TIR-TIR interactions remain obscure.

The functional diversity of TIR domains is confirmed by our observation that the sequence features common for all TIR domains are restricted to the structural core, which has minimal or no surface exposure (Fig. 2e) and, therefore, cannot be directly associated with a specific binding or catalytic function. This observed diversity and complexity of TIR functions emphasizes the need for automated, computational methods to analyze and classify the large numbers of TIR sequences into smaller, functionally related subgroups. Our study has applied Bayesian partitioning with pattern selection (BPPS) to automatically classify TIR domains based on those sequence motifs that best distinguish each group. The algorithm was applied to phylogenetically diverse TIR domain sequences retrieved from the NCBI non-redundant (nr) and environmental (env_nr) protein sequence databases and from the translated NCBI EST database. This sequence pool reflects the state of global genome sequencing projects at the time of sampling and the abundance of proteins with TIR domains in individual genomes. Metazoan, plant, and bacterial TIRs were nearly equally represented in this set and together accounted for 95\% of the sequences (Fig. 1b). The two largest of the minor phylogenetic groups in this set, i.e., archaea and protozoans, together account for $\sim 1.5 \%$ of the sequences. The TIR domains referred to as of "unknown" phylogenetic origin (Fig. 1b) corresponded to $\sim 3 \%$ of the total; these sequences were derived from environmental samples and co-partitioned with bacterial groups (Fig. 1c, g).

Results of partitioning have clearly demonstrated the biological significance of identified groups and confirmed BPPS as a valuable method for exploration and analysis of large sets of related, but functionally diverse protein sequences. Many traits indicate the validity of BPPS for functional analysis of TIR domains. First, the analysis has clearly differentiated phylogenetically distant sequences. Thus, representatives of three main taxonomic categories of the analyzed sequences, i.e., prokaryotic, plant, and metazoan TIRs, partitioned separately with only group 17 combining the bacterial TIRs with TIRs of protozoans and lower metazoans (Fig. 1c).

The second indication of the functional relatedness of individual groups is that, in most cases, the algorithm has automatically grouped architecturally similar eukaryotic TIRs to the same groups. For example, the plant TIR domains formed 3 groups, each of which is characterized by similar domain architectures among full-length proteins. The largest group of plant TIR domains (and of the entire partitioning), group 2, is 
formed by the NB-LRR family of pathogen-sensing receptors. The predominant domain architecture for proteins with other two types of plant TIR domains, i.e., groups 21 and 16, suggests that these TIRs belong to adapter proteins and protein kinases, respectively. Notably, the size of group 2 is larger than the sizes of other two Streptophyta groups by more than an order of magnitude. This significant size difference is however consistent with the relative abundance of corresponding genes in plant genomes (Van der Biezen and Jones 1998). This correlation is another clear indication that the sequence features identified by BPPS for groups of TIRs are functionally important.

Unlike most eukaryotic TIR groups, the prokaryotic groups typically contain proteins with different domain architectures. This likely reflects faster evolution together with sparser sampling of prokaryotic TIRs. It should be noted that the physiological functions of prokaryotic TIR domains are much less studied compared with that of eukaryotes. Moreover, only 3 experimentally determined structures of prokaryotic TIRs are currently available, all of which belong to just one group. The lack of specific biochemical and structural data on the prokaryotic TIRs makes it difficult to assess the functional implications. For this reason, most prokaryotic groups are not reviewed in detail here. Nevertheless, the motifs defining bacterial subgroups are important for understanding the diversity of prokaryotic TIR functions and should be instructive for planning future research. For this reason, motifs for prokaryotic TIR groups are published in Supplemental Fig. 1 as a series of contrast alignments.

The third line of evidence indicating the biological significance of identified groups is the remarkable conservation of regional backbone fold variants observed within individual groups. Thus, each group with multiple structural representatives can be uniquely characterized by a highly conserved backbone configuration of the fourth helical region (Fig. 4ac). Each fold variant is associated with a group-specific motif presumably responsible for the fold (Figs. 3c, 5e, and 12d).

BPPS identification of four large, conserved surface patches, which are formed by the surface-exposed side of $\alpha$-helices $C^{\prime \prime}$ and short $3_{10}$-helices D in TIRs of groups 10 and 23 (Figs. 8c, d and $9 \mathrm{~d}, \mathrm{e}$ ), is, in our opinion, another significant result. These group-defining surface features are highly conserved in proteins related to TIRAP (group 10) and to MyD88 (group 23) (Figs. $8 \mathrm{a}$ and 9a). Current models of adapter recruitment to activated TLRs suggest that the third and fourth helical regions belong to two of the four TIR sites mediating signal-dependent assembly of signaling complexes. The sites, which include $\alpha \mathrm{Cs}$ and $310^{-}$ helices D (previously termed "sites 2 and 3"; (Toshchakov and Javmen 2020), were deemed highly multispecific, being able to mutually interact with the corresponding helical region of TIRAP, MyD88, or a TLR TIR (Couture et al. 2012; Javmen et al. 2018; Toshchakov and Javmen 2020; Ve et al. 2017; Fig. $8 \mathrm{e})$. This discovery of conserved surface patches, each of which corresponds to a multispecific interaction site within adapters TIRAP and MyD88, suggests mechanisms of TIR-TIR recognition in signaling.

BPPS confirms the TIR domain Box 2 and 3 motifs identified by Slack et al. (2000) and identifies the groups associated with these motifs: the Box 2 motif (-RDxxPG-) is present in group 3 (the Toll proteins and TLRs), group 4 (the IL-1R family), group 10 (TIRAP orthologs), and both groups of MyD88-like TIRs (group 32 of arthropod TIRs and group 23 of other metazoan TIRs). Box 2 is typically absent in prokaryotic TIRs, except perhaps the TIRs of group 28, in which the BB loop motif $\left(-\mathrm{W}_{9} \mathbf{D}_{9} \mathbf{F}_{\mathbf{7}} \mathbf{V}_{\mathbf{6}} \mathbf{P}_{\mathbf{7}} \mathbf{G}_{\mathbf{9}}\right.$-) resembles Box 2 for the most part (Supplemental Fig. 1). Box 3 (-FW- in the Nterminal round of $\alpha \mathrm{E}$ ) features the same groups of eukaryotic TIRs as does Box 2, with the exception of group 10 (TIRAPrelated TIRs). The Box 3 motif is absent from prokaryotic TIRs.

BPPS conclusively clarifies the functional significance of Boxes 2 and 3, each of which is in fact part of a larger conserved group of intramolecularly interacting residues. Thus, the presence of Box 3 within a group, in all available cases, signified the presence of conserved aromatic or sulfurcontaining residues at group-specific positions in $\alpha \mathrm{A}$ and $\beta E$. Notably, in all TIR structures with a Box 3 , these residues, although distantly located in the sequence (Figs. 5a and 6a), establish mutual contacts (Figs. 5d and 6c). Analogously, the presence of Box 2 in a TIR group in all cases correlated with the presence of an acidic residue in $\alpha$ A, i.e., $12-14$ residues away from R36 of Box 2 (Figs. 5a, 6a, 8a, and 9a, b). The charged residues of Box 2 contact the conserved negatively charged residue of $\alpha \mathrm{A}$ through salt bridges and hydrogen bonds in groups 3 and 4 , and in certain conformations of group 10 TIRs (Figs. 5c, 6d, and not shown). Many lines of evidence indicate that the region near $\beta \mathrm{B}$ is conformationally flexible (see, for example, Hughes et al. 2017); therefore, it is not surprising that these interactions are absent from some conformation variants (e.g., see Fig. 9f).

Funding information This work was supported in part by the National Institute of Allergy and Infectious Diseases grant AI082299 (VYT) and by National Institute of General Medical Sciences grant R01GM125878 (AFN).

Open Access This article is licensed under a Creative Commons Attribution 4.0 International License, which permits use, sharing, adaptation, distribution and reproduction in any medium or format, as long as you give appropriate credit to the original author(s) and the source, provide a link to the Creative Commons licence, and indicate if changes were made. The images or other third party material in this article are included in the article's Creative Commons licence, unless indicated otherwise in a credit line to the material. If material is not included in the article's Creative Commons licence and your intended use is not permitted by statutory regulation or exceeds the permitted use, you will need to obtain permission directly from the copyright holder. To view a copy of this licence, visit http://creativecommons.org/licenses/by/4.0/. 


\section{References}

Agarwala R, Barrett T, Beck J, Benson DA, Bollin C, Bolton E, Bourexis D, Brister JR, Bryant SH, Canese K, Cavanaugh M, Charowhas C, Clark K, Dondoshansky I, Feolo M, Fitzpatrick L, Funk K, Geer LY, Gorelenkov V, Graeff A, Hlavina W, Holmes B, Johnson M, Kattman B, Khotomlianski V, Kimchi A, Kimelman M, Kimura M, Kitts P, Klimke W, Kotliarov A, Krasnov S, Kuznetsov A, Landrum MJ, Landsman D, Lathrop S, Lee JM, Leubsdorf C, Lu Z, Madden TL, Marchler-Bauer A, Malheiro A, Meric P, Karsch-Mizrachi I, Mnev A, Murphy T, Orris R, Ostell J, O'Sullivan C, Palanigobu V, Panchenko AR, Phan L, Pierov B, Pruitt KD, Rodarmer K, Sayers EW, Schneider V, Schoch CL, Schuler GD, Sherry ST, Siyan KS, Oboleva A, Soussov V, Starchenko G, Tatusova TA, Thibaud-Nissen F, Todorov K, Trawick BW, Vakatov D, Ward M, Yaschenko E, Zasypkin A, Zbicz K (2018) Database resources of the National Center for Biotechnology Information. Nucleic Acids Res 46:D8-D13

Alaidarous M, Ve T, Casey LW, Valkov E, Ericsson DJ, Ullah MO, Schembri MA, Mansell A, Sweet MJ, Kobe B (2014) Mechanism of bacterial interference with TLR4 signaling by Brucella Toll/interleukin-1 receptor domain-containing protein TcpB. J Biol Chem 289:654-668

Anderson KV, Jurgens G, Nusslein-Volhard C (1985) Establishment of dorsal-ventral polarity in the Drosophila embryo: genetic studies on the role of the Toll gene product. Cell 42:779-789

Bernoux M, Ve T, Williams S, Warren C, Hatters D, Valkov E, Zhang X, Ellis JG, Kobe B, Dodds PN (2011) Structural and functional analysis of a plant resistance protein TIR domain reveals interfaces for self-association, signaling, and autoregulation. Cell Host Microbe 9: 200-211

Boller T, Felix G (2009) A renaissance of elicitors: perception of microbe-associated molecular patterns and danger signals by pattern-recognition receptors. Annu Rev Plant Biol 60:379-406

Boraschi D, Tagliabue A (2013) The interleukin-1 receptor family. Semin Immunol 25:394-407

Bosch TC, Augustin R, Anton-Erxleben F, Fraune S, Hemmrich G, Zill H, Rosenstiel P, Jacobs G, Schreiber S, Leippe M, Stanisak M, Grotzinger J, Jung S, Podschun R, Bartels J, Harder J, Schroder JM (2009) Uncovering the evolutionary history of innate immunity: the simple metazoan Hydra uses epithelial cells for host defence. Dev Comp Immunol 33:559-569

Buchmann K (2014) Evolution of innate immunity: clues from invertebrates via fish to mammals. Front Immunol 5:459

Carlsson E, Ding JL, Byrne B (2016) SARM modulates MyD88mediated TLR activation through BB-loop dependent TIR-TIR interactions. Biochim Biophys Acta 1863:244-253

Chan SL, Low LY, Hsu S, Li S, Liu T, Santelli E, Le Negrate G, Reed JC, Woods VL Jr, Pascual J (2009) Molecular mimicry in innate immunity: crystal structure of a bacterial TIR domain. J Biol Chem 284: 21386-21392

Chan SL, Mukasa T, Santelli E, Low LY, Pascual J (2010) The crystal structure of a TIR domain from Arabidopsis thaliana reveals a conserved helical region unique to plants. Protein Sci 19:155-161

Cirl C, Wieser A, Yadav M, Duerr S, Schubert S, Fischer H, Stappert D, Wantia N, Rodriguez N, Wagner H, Svanborg C, Miethke T (2008) Subversion of Toll-like receptor signaling by a unique family of bacterial Toll/interleukin-1 receptor domain-containing proteins. Nat Med 14:399-406

Couture LA, Piao W, Ru LW, Vogel SN, Toshchakov VY (2012) Targeting Toll-like receptor (TLR) signaling by Toll/interleukin-1 receptor (TIR) domain-containing adapter protein/MyD88 adapterlike (TIRAP/Mal)-derived decoy peptides. J Biol Chem 287:2464124648
Dodds PN, Rathjen JP (2010) Plant immunity: towards an integrated view of plant-pathogen interactions. Nat Rev Genet 11:539-548

Enokizono Y, Kumeta H, Funami K, Horiuchi M, Sarmiento J, Yamashita K, Standley DM, Matsumoto M, Seya T, Inagaki F (2013) Structures and interface mapping of the TIR domaincontaining adaptor molecules involved in interferon signaling. Proc Natl Acad Sci U S A 110:19908-19913

Essuman K, Summers DW, Sasaki Y, Mao X, DiAntonio A, Milbrandt J (2017) The SARM1 Toll/interleukin-1 receptor domain possesses intrinsic $\mathrm{NAD}(+)$ cleavage activity that promotes pathological axonal degeneration. Neuron 93:1334-1343 e5

Essuman K, Summers DW, Sasaki Y, Mao X, Yim AKY, DiAntonio A, Milbrandt J (2018) TIR domain proteins are an ancient family of NAD(+)-consuming enzymes. Curr Biol 28:421-430 e4

Ferrao R, Li J, Bergamin E, Wu H (2012) Structural insights into the assembly of large oligomeric signalosomes in the Toll-like receptor-interleukin-1 receptor superfamily. Sci Signal 5:re3

Fitzgerald KA, Palsson-McDermott EM, Bowie AG, Jefferies CA, Mansell AS, Brady G, Brint E, Dunne A, Gray P, Harte MT, McMurray D, Smith DE, Sims JE, Bird TA, O’Neill LA (2001) Mal (MyD88-adapter-like) is required for Toll-like receptor-4 signal transduction. Nature 413:78-83

Flajnik MF, Kasahara M (2010) Origin and evolution of the adaptive immune system: genetic events and selective pressures. Nat Rev Genet 11:47-59

Garlanda C, Dinarello CA, Mantovani A (2013) The interleukin-1 family: back to the future. Immunity 39:1003-1018

Gauthier ME, Du Pasquier L, Degnan BM (2010) The genome of the sponge Amphimedon queenslandica provides new perspectives into the origin of Toll-like and interleukin 1 receptor pathways. Evol Dev 12:519-533

Gay NJ, Keith FJ (1991) Drosophila Toll and IL-1 receptor. Nature 351: 355-356

Gay NJ, Symmons MF, Gangloff M, Bryant CE (2014) Assembly and localization of Toll-like receptor signaling complexes. Nat Immunol 2014:546-558

Gerdts J, Summers DW, Sasaki Y, DiAntonio A, Milbrandt J (2013) Sarm1-mediated axon degeneration requires both SAM and TIR interactions. J Neurosci 33:13569-13580

Guex N, Peitsch MC (1997) SWISS-MODEL and the Swiss-PdbViewer: an environment for comparative protein modeling. Electrophoresis 18:2714-2723

Hardiman G, Rock FL, Balasubramanian S, Kastelein RA, Bazan JF (1996) Molecular characterization and modular analysis of human MyD88. Oncogene 13:2467-2475

Horng T, Medzhitov R (2001) Drosophila MyD88 is an adapter in the Toll signaling pathway. Proc Natl Acad Sci U S A 98:12654-12658

Horng T, Barton GM, Medzhitov R (2001) TIRAP: an adapter molecule in the Toll signaling pathway. Nat Immunol 2:835-841

Horsefield S, Burdett H, Zhang X, Manik MK, Shi Y, Chen J, Qi T, Gilley J, Lai JS, Rank MX, Casey LW, Gu W, Ericsson DJ, Foley G, Hughes RO, Bosanac T, von Itzstein M, Rathjen JP, Nanson JD, Boden M, Dry IB, Williams SJ, Staskawicz BJ, Coleman MP, Ve T, Dodds PN, Kobe B (2019) NAD(+) cleavage activity by animal and plant TIR domains in cell death pathways. Science 365:793-799

Hughes MM, Lavrencic P, Coll RC, Ve T, Ryan DG, Williams NC, Menon D, Mansell A, Board PG, Mobli M, Kobe B, O'Neill LAJ (2017) Solution structure of the TLR adaptor MAL/TIRAP reveals an intact BB loop and supports MAL Cys91 glutathionylation for signaling. Proc Natl Acad Sci U S A 114:E6480-E6489

Hyun KG, Lee Y, Yoon J, Yi H, Song JJ (2016) Crystal structure of Arabidopsis thaliana SNC1 TIR domain. Biochem Biophys Res Commun 481:146-152

Jang TH, Park HH (2014) Crystal structure of TIR domain of TLR6 reveals novel dimeric interface of TIR-TIR interaction for toll-like receptor signaling pathway. J Mol Biol 426:3305-3313 
Javmen A, Szmacinski H, Lakowicz JR, Toshchakov VY (2018) Blocking TIR domain interactions in TLR9 signaling. J Immunol 201:995-1006

Jiang Z, Georgel P, Li C, Choe J, Crozat K, Rutschmann S, Du X, Bigby T, Mudd S, Sovath S, Wilson IA, Olson A, Beutler B (2006) Details of Toll-like receptor:adapter interaction revealed by germ-line mutagenesis. Proc Natl Acad Sci U S A 103:10961-10966

Kagan JC, Magupalli VG, Wu H (2014) SMOCs: supramolecular organizing centres that control innate immunity. Nat Rev Immunol 14: $821-826$

Kawai T, Akira S (2011) Toll-like receptors and their crosstalk with other innate receptors in infection and immunity. Immunity 34:637-650

Khan JA, Brint EK, O'Neill LA, Tong L (2004) Crystal structure of the Toll/interleukin-1 receptor domain of human IL-1RAPL. J Biol Chem 279:31664-31670

Lee Y, Whang I, Umasuthan N, De Zoysa M, Oh C, Kang DH, Choi CY, Park CJ, Lee J (2011) Characterization of a novel molluscan MyD88 family protein from manila clam, Ruditapes philippinarum. Fish Shellfish Immunol 31:887-893

Lemaitre B, Nicolas E, Michaut L, Reichhart JM, Hoffmann JA (1996) The dorsoventral regulatory gene cassette spatzle/Toll/cactus controls the potent antifungal response in Drosophila adults. Cell 86: 973-983

Letunic I, Bork P (2018) 20 years of the SMART protein domain annotation resource. Nucleic Acids Res 46:D493-D496

Lin Z, Lu J, Zhou W, Shen Y (2012) Structural insights into TIR domain specificity of the bridging adaptor Mal in TLR4 signaling. PLoS One 7:e34202

Liongue C, Sertori R, Ward AC (2016) Evolution of cytokine receptor signaling. J Immunol 197:11-18

Marek LR, Kagan JC (2012) Phosphoinositide binding by the Toll adaptor dMyD88 controls antibacterial responses in Drosophila. Immunity 36:612-622

Medzhitov R, Preston-Hurlburt P, Janeway CA Jr (1997) A human homologue of the Drosophila Toll protein signals activation of adaptive immunity. Nature 388:394-397

Medzhitov R, Preston-Hurlburt P, Kopp E, Stadlen A, Chen C, Ghosh S, Janeway CA Jr (1998) MyD88 is an adaptor protein in the hToll/IL1 receptor family signaling pathways. Mol Cell 2:253-258

Mink M, Fogelgren B, Olszewski K, Maroy P, Csiszar K (2001) A novel human gene (SARM) at chromosome 17q11 encodes a protein with a SAM motif and structural similarity to Armadillo/beta-catenin that is conserved in mouse, Drosophila, and Caenorhabditis elegans. Genomics 74:234-244

Nanson JD, Kobe B, Ve T (2019) Death, TIR, and RHIM: selfassembling domains involved in innate immunity and cell-death signaling. J Leukoc Biol 105:363-375

Neuwald AF (2009) Rapid detection, classification and accurate alignment of up to a million or more related protein sequences. Bioinformatics 25:1869-1875

Neuwald AF (2014a) A Bayesian sampler for optimization of protein domain hierarchies. J Comput Biol 21:269-286

Neuwald AF (2014b) Protein domain hierarchy Gibbs sampling strategies. Stat Appl Genet Mol Biol 13:497-517

Neuwald AF, Kannan N, Poleksic A, Hata N, Liu JS (2003) Ran's Cterminal, basic patch, and nucleotide exchange mechanisms in light of a canonical structure for Rab, Rho, Ras, and Ran GTPases. Genome Res 13:673-692

Nie L, Cai SY, Shao JZ, Chen J (2018) Toll-like receptors, associated biological roles, and signaling networks in non-mammals. Front Immunol 9:1523

Nyman T, Stenmark P, Flodin S, Johansson I, Hammarstrom M, Nordlund P (2008) The crystal structure of the human toll-like receptor 10 cytoplasmic domain reveals a putative signaling dimer. J Biol Chem 283:11861-11865
O’Neill LA, Fitzgerald KA, Bowie AG (2003) The Toll-IL-1 receptor adaptor family grows to five members. Trends Immunol 24:286290

Ohnishi H, Tochio H, Kato Z, Orii KE, Li A, Kimura T, Hiroaki H, Kondo N, Shirakawa M (2009) Structural basis for the multiple interactions of the MyD88 TIR domain in TLR4 signaling. Proc Natl Acad Sci U S A 106:10260-10265

Oshiumi H, Matsumoto M, Funami K, Akazawa T, Seya T (2003) TICAM-1, an adaptor molecule that participates in Toll-like receptor 3-mediated interferon-beta induction. Nat Immunol 4:161-167

Osterloh JM, Yang J, Rooney TM, Fox AN, Adalbert R, Powell EH, Sheehan AE, Avery MA, Hackett R, Logan MA, MacDonald JM, Ziegenfuss JS, Milde S, Hou YJ, Nathan C, Ding A, Brown RH Jr, Conforti L, Coleman M, Tessier-Lavigne M, Zuchner S, Freeman MR (2012) dSarm/Sarm1 is required for activation of an injuryinduced axon death pathway. Science 337:481-484

Pawson T, Nash P (2003) Assembly of cell regulatory systems through protein interaction domains. Science 300:445-452

Piao WJ, Ru LW, Piepenbrink KH, Sundberg EJ, Vogel SN, Toshchakov VY (2013) Recruitment of TLR adapter TRIF to TLR4 signaling complex is mediated by the second helical region of TRIF TIR domain. Proc Natl Acad Sci U S A 110:19036-19041

Rana RR, Zhang M, Spear AM, Atkins HS, Byrne B (2013) Bacterial TIR-containing proteins and host innate immune system evasion. Med Microbiol Immunol 202:1-10

Ren Q, Chen YH, Ding ZF, Huang Y, Shi YR (2014) Identification and function of two myeloid differentiation factor 88 variants in triangleshell pearl mussel (Hyriopsis cumingii). Dev Comp Immunol 42: 286-293

Richardson JS, Richardson DC (2002) Natural beta-sheet proteins use negative design to avoid edge-to-edge aggregation. Proc Natl Acad Sci U S A 99:2754-2759

Rivers-Auty J, Daniels MJD, Colliver I, Robertson DL, Brough D (2018) Redefining the ancestral origins of the interleukin-1 superfamily. Nat Commun 9:1156

Roach JC, Glusman G, Rowen L, Kaur A, Purcell MK, Smith KD, Hood LE, Aderem A (2005) The evolution of vertebrate Toll-like receptors. Proc Natl Acad Sci U S A 102:9577-9582

Rock FL, Hardiman G, Timans JC, Kastelein RA, Bazan JF (1998) A family of human receptors structurally related to Drosophila Toll. Proc Natl Acad Sci U S A 95:588-593

Slack JL, Schooley K, Bonnert TP, Mitcham JL, Qwarnstrom EE, Sims JE, Dower SK (2000) Identification of two major sites in the type I interleukin-1 receptor cytoplasmic region responsible for coupling to pro-inflammatory signaling pathways. J Biol Chem 275:46704678

Snyder GA, Cirl C, Jiang J, Chen K, Waldhuber A, Smith P, Rommler F, Snyder N, Fresquez T, Durr S, Tjandra N, Miethke T, Xiao TS (2013) Molecular mechanisms for the subversion of MyD88 signaling by TcpC from virulent uropathogenic Escherichia coli. Proc Natl Acad Sci U S A 110:6985-6990

Snyder GA, Deredge D, Waldhuber A, Fresquez T, Wilkins DZ, Smith PT, Durr S, Cirl C, Jiang J, Jennings W, Luchetti T, Snyder N, Sundberg EJ, Wintrode P, Miethke T, Xiao TS (2014) Crystal structures of the Toll/interleukin-1 receptor (TIR) domains from the Brucella protein TcpB and host adaptor TIRAP reveal mechanisms of molecular mimicry. J Biol Chem 289:669-679

Spear AM, Loman NJ, Atkins HS, Pallen MJ (2009) Microbial TIR domains: not necessarily agents of subversion? Trends Microbiol 17:393-398

Spoel SH, Dong X (2012) How do plants achieve immunity? Defence without specialized immune cells. Nat Rev Immunol 12:89-100

Sullivan C, Postlethwait JH, Lage CR, Millard PJ, Kim CH (2007) Evidence for evolving Toll-IL-1 receptor-containing adaptor molecule function in vertebrates. J Immunol 178:4517-4527 
Summers DW, Gibson DA, DiAntonio A, Milbrandt J (2016) SARM1specific motifs in the TIR domain enable NAD+ loss and regulate injury-induced SARM1 activation. Proc Natl Acad Sci U S A 113: E6271-E6280

Tassia MG, Whelan NV, Halanych KM (2017) Toll-like receptor pathway evolution in deuterostomes. Proc Natl Acad Sci U S A 114: 7055-7060

Toshchakov VY, Javmen A (2020) Targeting the TLR signalosome with TIR domain-derived cell-permeable decoy peptides: the current state and perspectives. Innate Immun 26:35-47

Toshchakov VY, Szmacinski H, Couture LA, Lakowicz JR, Vogel SN (2011) Targeting TLR4 signaling by TLR4 Toll/IL-1 receptor domain-derived decoy peptides: identification of the TLR4 Toll/IL-1 receptor domain dimerization interface. J Immunol 186: 4819-4827

Urbach JM, Ausubel FM (2017) The NBS-LRR architectures of plant Rproteins and metazoan NLRs evolved in independent events. Proc Natl Acad Sci U S A 114:1063-1068

Valkov E, Stamp A, Dimaio F, Baker D, Verstak B, Roversi P, Kellie S, Sweet MJ, Mansell A, Gay NJ, Martin JL, Kobe B (2011) Crystal structure of Toll-like receptor adaptor MAL/TIRAP reveals the molecular basis for signal transduction and disease protection. Proc Natl Acad Sci U S A 108:14879-14884

Van der Biezen EA, Jones JD (1998) Plant disease-resistance proteins and the gene-for-gene concept. Trends Biochem Sci 23:454-456

van der Burg CA, Prentis PJ, Surm JM, Pavasovic A (2016) Insights into the innate immunome of actiniarians using a comparative genomic approach. BMC Genomics 17:850

Ve T, Williams SJ, Kobe B (2015) Structure and function of Toll/interleukin-1 receptor/resistance protein (TIR) domains. Apoptosis 20:250-261

Ve T, Vajjhala PR, Hedger A, Croll T, DiMaio F, Horsefield S, Yu X, Lavrencic P, Hassan Z, Morgan GP, Mansell A, Mobli M, O'Carroll A, Chauvin B, Gambin Y, Sierecki E, Landsberg MJ, Stacey KJ, Egelman EH, Kobe B (2017) Structural basis of TIR-domainassembly formation in MAL- and MyD88-dependent TLR4 signaling. Nat Struct Mol Biol 24:743-751

Venkatesh B, Lee AP, Ravi V, Maurya AK, Lian MM, Swann JB, Ohta Y, Flajnik MF, Sutoh Y, Kasahara M, Hoon S, Gangu V, Roy SW, Irimia M, Korzh V, Kondrychyn I, Lim ZW, Tay BH, Tohari S, Kong KW, Ho S, Lorente-Galdos B, Quilez J, Marques-Bonet T, Raney BJ, Ingham PW, Tay A, Hillier LW, Minx P, Boehm T, Wilson RK, Brenner S, Warren WC (2014) Elephant shark genome provides unique insights into gnathostome evolution. Nature 505: 174-179

Wan L, Essuman K, Anderson RG, Sasaki Y, Monteiro F, Chung EH, Osborne Nishimura E, DiAntonio A, Milbrandt J, Dangl JL, Nishimura MT (2019) TIR domains of plant immune receptors are $\mathrm{NAD}(+)$-cleaving enzymes that promote cell death. Science 365 : 799-803
Wang T, Secombes CJ (2013) The cytokine networks of adaptive immunity in fish. Fish Shellfish Immunol 35:1703-1718

Weisse RH-J, Scheidig AJ (2015) Crystal structure of the TIR domain of the Toll-related receptor TRR-2 from the lower metazoan Hydra magnipapillata (crystal form II)

Wesche H, Henzel WJ, Shillinglaw W, Li S, Cao Z (1997) MyD88: an adapter that recruits IRAK to the IL-1 receptor complex. Immunity 7:837-847

Whitham S, Dinesh-Kumar SP, Choi D, Hehl R, Corr C, Baker B (1994) The product of the tobacco mosaic virus resistance gene N: similarity to toll and the interleukin-1 receptor. Cell 78:1101-1115

Wiens M, Korzhev M, Perovic-Ottstadt S, Luthringer B, Brandt D, Klein S, Muller WE (2007) Toll-like receptors are part of the innate immune defense system of sponges (demospongiae: Porifera). Mol Biol Evol 24:792-804

Williams SJ, Sohn KH, Wan L, Bernoux M, Sarris PF, Segonzac C, Ve T, Ma Y, Saucet SB, Ericsson DJ, Casey LW, Lonhienne T, Winzor DJ, Zhang X, Coerdt A, Parker JE, Dodds PN, Kobe B, Jones JD (2014) Structural basis for assembly and function of a heterodimeric plant immune receptor. Science 344:299-303

Williams SJ, Yin L, Foley G, Casey LW, Outram MA, Ericsson DJ, Lu J, Boden M, Dry IB, Kobe B (2016) Structure and function of the TIR domain from the grape NLR protein RPV1. Front Plant Sci 7:1850

Woo JR, Kim S, Shoelson SE, Park S (2012) X-ray crystallographic structure of TIR-domain from the human TIR-domain containing adaptor protein/MyD88-adaptor-like protein (TIRAP/MAL). Bull Kor Chem Soc 33:3091-3094

Wright PE, Dyson HJ (2015) Intrinsically disordered proteins in cellular signalling and regulation. Nat Rev Mol Cell Biol 16:18-29

Xu Y, Tao X, Shen B, Horng T, Medzhitov R, Manley JL, Tong L (2000) Structural basis for signal transduction by the Toll/interleukin-1 receptor domains. Nature 408:111-115

Yamamoto M, Sato S, Mori K, Hoshino K, Takeuchi O, Takeda K, Akira S (2002) Cutting edge: a novel Toll/IL-1 receptor domaincontaining adapter that preferentially activates the IFN-beta promoter in the Toll-like receptor signaling. J Immunol 169:6668-6672

Zhang Q, Zmasek CM, Cai X, Godzik A (2011) TIR domain-containing adaptor SARM is a late addition to the ongoing microbe-host dialog. Dev Comp Immunol 35:461-468

Zhang X, Bernoux M, Bentham AR, Newman TE, Ve T, Casey LW, Raaymakers TM, Hu J, Croll TI, Schreiber KJ, Staskawicz BJ, Anderson PA, Sohn KH, Williams SJ, Dodds PN, Kobe B (2017) Multiple functional self-association interfaces in plant TIR domains. Proc Natl Acad Sci U S A 114:E2046-E2052

Publisher's note Springer Nature remains neutral with regard to jurisdictional claims in published maps and institutional affiliations. 